\title{
The AP2/ERF Gene Family in Triticum durum: Genome-Wide Identification and Expression Analysis under Drought and Salinity Stresses
}

\author{
Sahar Faraji ${ }^{1}$, Ertugrul Filiz ${ }^{2}{ }^{\circledR}$, Seyed Kamal Kazemitabar ${ }^{1}$, Alessandro Vannozzi ${ }^{3}{ }^{\circledR}$, \\ Fabio Palumbo ${ }^{3}$ (D) Gianni Barcaccia ${ }^{3}$ (D) and Parviz Heidari ${ }^{4} *$ (D) \\ 1 Department of Plant Breeding, Faculty of Crop Sciences, Sari Agricultural Sciences and Natural Resources \\ University (SANRU), Sari 4818166996, Iran; sahar.faraji@rocketmail.com (S.F.); sdklkr@ymail.com (S.K.K.) \\ 2 Department of Crop and Animal Production, Cilimli Vocational School, Duzce University, \\ Duzce 81750, Turkey; ertugrulfiliz@gmail.com \\ 3 Laboratory of Genomics for Breeding, DAFNAE, Campus of Agripolis, University of Padova, Legnaro, \\ 35020 Padova, Italy; alessandro.vannozzi@unipd.it (A.V.); fabio.palumbo@unipd.it (F.P.); \\ gianni.barcaccia@unipd.it (G.B.) \\ 4 Faculty of Agriculture, Shahrood University of Technology, Shahrood 3619995161, Iran \\ * Correspondence: heidarip@shahroodut.ac.ir; Tel.: +98-912-0734-034
}

Received: 3 November 2020; Accepted: 3 December 2020; Published: 7 December 2020

\begin{abstract}
Members of the AP2/ERF transcription factor family play critical roles in plant development, biosynthesis of key metabolites, and stress response. A detailed study was performed to identify TtAP2s/ERFs in the durum wheat (Triticum turgidum ssp. durum) genome, which resulted in the identification of 271 genes distributed on chromosomes $1 \mathrm{~A}-7 \mathrm{~B}$. By carrying 27 genes, chromosome $6 \mathrm{~A}$ had the highest number of TtAP2s/ERFs. Furthermore, a duplication assay of TtAP2s/ERFs demonstrated that 70 duplicated gene pairs had undergone purifying selection. According to RNA-seq analysis, the highest expression levels in all tissues and in response to stimuli were associated with $D R F$ and ERF subfamily genes. In addition, the results revealed that TtAP2/ERF genes have tissue-specific expression patterns, and most TtAP2/ERF genes were significantly induced in the root tissue. Additionally, 13 TtAP2/ERF genes (six ERFs, three DREBs, two DRFs, one AP2, and one $R A V$ ) were selected for further analysis via qRT-PCR of their potential in coping with drought and salinity stresses. The TtAP2/ERF genes belonging to the DREB subfamily were markedly induced under both drought-stress and salinity-stress conditions. Furthermore, docking simulations revealed several residues in the pocket sites of the proteins associated with the stress response, which may be useful in future site-directed mutagenesis studies to increase the stress tolerance of durum wheat. This study could provide valuable insights for further evolutionary and functional assays of this important gene family in durum wheat.
\end{abstract}

Keywords: AP2/ERF gene family; Triticum durum; gene expression; genome sequence; abiotic stresses

\section{Introduction}

Various abiotic and biotic stresses, such as plant pathogens, drought, cold, heat, and salinity, have destructive effects on the growth and development of plant species. Plants employ complex regulatory pathways to address various stimuli, which include stress sensing, signal transduction, and regulation of stress-responsive genes and/or proteins eventually manifested at the cellular and physiological levels [1,2]. The modulation of gene expression in response to stresses is highly controlled by specific transcription factors (TFs), which simultaneously mediate the transcription of a vast number of downstream stress-responsive genes $[3,4]$. TFs have been extensively proposed to be significant 
regulatory proteins involved in modifying plant growth and the stress response [5,6]. Among the members of multiple TF groups, the members of the APETALA2/ethylene-responsive factor (AP2/ERF) superfamily have multiple functions in plant development and play roles in the biosynthesis of many key metabolites, providing the ability to address environmental stress [7]. Accordingly, understanding the molecular functions of these gene family members can be helpful for the improvement of crop plant compatibility and yield under various unfavorable situations.

AP2/ERF family-related proteins, which compose a large family, play essential roles in plant growth, enlargement, and coping with different stresses such as extreme chilling/heat, drought, and high-salinity conditions as well as infection by viral and microbial pathogens [8-10]. A large number of AP2/ERF genes have been recognized in various plant species, such as Arabidopsis [11], bread wheat [12], soybean [13], rice [9], Brassica napus [14], Medicago sativa [15], pineapple [16], Camptotheca acuminata [17], orchardgrass [18], foxtail millet [19], sorghum [20], ginseng [21], and Gynostemma pentaphyllum [22]. Three main clades of AP2/ERF family members have been determined based on the domain number: the ERF subfamily, whose members contain a single AP2 domain; the AP2 subfamily, whose members contain two AP2 domains connected by a 25 amino acid linker; and the RAV subfamily, whose members have a single AP2 domain and an additional B3 DNA-binding motif [19]. AP2 subfamily genes have been reported to be the main regulatory factors involved in organ development, including spikelet meristem differentiation, leaf epidermal cell designation, floral organ patterning, and seed yield [23-25]. Members of the RAV group of the AP2/ERF family also have important functions in plant hormone signal transduction and the regulation of responses to biotic and abiotic stimuli [26,27]. Dehydration-responsive element-binding (DREB) members, as important plant-specific transcription factor, also belong to the AP2/ERF superfamily and are involved in response to abiotic stresses [28]. Furthermore, various studies have reported the involvement of DREBs and other ERF members in dealing with water deficit [29,30], cold, and oxidative [31] and salinity [32,33] stresses. Cui et al. reported that $11 B d A P 2 / E R F$ genes are involved in various developmental and physiological processes during the Brachypodium distachyon life cycle [34]. Furthermore, Kavas et al. indicated higher expression levels of PvAP2-ERF111, PvAP2-ERF119, PvAP2-ERF72, and PvAP2-ERF150 genes in common bean leaf tissues after salt treatment, suggesting the involvement of these genes in salt stress signal transduction [35]. Ma et al. identified a novel AP2/ERF gene from rice, OsRPH1, that negatively controls plant height [36]. Additionally, a novel ERF gene, ZmERF105, was isolated from maize that positively controls resistance to Exserohilum turcicum [37]. In addition, the members of the AP2/ERF gene family regulate the biosynthesis of many key metabolites, such as terpenoid indole alkaloids, nicotine, steroidal glycoalkaloids, tanshinone, and phenolic acids [38,39].

The genome of tetraploid wheat (Triticum turgidum ssp. durum) is approximately $10.45 \mathrm{~Gb}$, and this subspecies is frequently used to provide nutrition via noodles and pasta making. Very few AP2/ERF genes have been distinguished and characterized in the durum wheat genome to date [29,30,32,40], and no computational biological evaluation of the AP2/ERF family has been performed in this important crop species. In the present study, members of the AP2/ERF gene family were identified in the durum wheat genome, and multiple structural and functional characterizations were carried out. The results of this study provide further insights concerning the regulatory roles of these genes in the development and stress response of durum wheat and provide knowledge on the evolutionary systems and molecular pathways affected by AP2/ERFs in durum wheat and its relatives.

\section{Materials and Methods}

\subsection{Identification of TtAP2/ERF Genes in the Genome of Durum Wheat}

For the identification of the members of the AP2/ERF gene family, the reference genome of Triticum turgidum was obtained from BioProject No. PRJEB22687 from the Ensembl database [41]. A hidden Markov model (HMM) search was conducted via the HMMER 3.0 program with the AP2 domain (PF00847) sequence used as a query (E-value $<\times 10^{-5}$ ), after which the retrieved protein 
sequences were searched against the content of the Pfam database [42] for the presence of the specific AP2 domain. Additionally, the identified TtAP2/ERF sequences were assessed through the SMART database [43], and any partial or low-quality AP2 domain-containing sequences were identified and removed from further characterization. The corresponding cDNA and genomic sequences of the identified TtAP2/ERF proteins were also distinguished among the sequenced contigs in the durum wheat genome, and the chromosomal location of the TtAP2/ERF genes was determined through gene ID searches in Ensembl (PRJEB22687). The ProtParam program of the ExPASy server [44] was utilized to determine the important physicochemical characteristics, such as the molecular weight (MW) and theoretical isoelectric point ( $p I$ ) of the TtAP2/ERF proteins. The CELLO program [45] was also employed to determine the subcellular location of each TtAP2/ERF protein as well as for gene ontology (GO) annotations of the TtAP2/ERF genes through the CELLO2GO tool.

\subsection{Chromosomal Mapping, Gene Duplications, and Estimation of Ka/Ks Values of the Duplicated Pairs}

The identified TtAP2/ERF genes were mapped onto the durum wheat chromosomes based on their predicted positions in Ensembl by using MapChart software (v. 2.32) [46]. The duplication events across TtAP2/ERF genes were detected by alignment of the TtAP2/ERF coding DNA sequences through the ClustalX program (v. 2.0) [47], after which BioEdit software (v. 7.2.5) was used to predict the identity matrix between the aligned CDSs [48]. The duplicated gene pairs were ultimately distinguished as genes sharing greater than $85 \%$ identity, as a threshold line, at the nucleotide sequence level, and were manually highlighted on the chromosomal map. To estimate the divergence of homologous $T t A P 2 \mathrm{~s} / E R F \mathrm{~s}$ and the selective pressure against the duplicated genes, DnaSP software (v. 6.0) was applied to calculate the Ks (synonymous) and Ka (nonsynonymous) replacement rate per site between the members of each gene pair [49].

\subsection{Phylogenetic Analysis and Motif Recognition}

To investigate the phylogenetic relationships, the AP2/ERF protein sequences from durum wheat as well as Oryza sativa and Arabidopsis thaliana, which were retrieved from the Plant TF Database [50], were employed to construct phylogenetic trees based on the neighbor-joining (NJ) method via MEGA software (v. 6.0) [51], and 1000 replicates were also selected for bootstrap analysis to represent the evolutionary history. The TtAP2/ERF protein sequences were also subjected to MEME software (v. 5.2.0) [52] for identification of conserved motifs. Protein sequences of the AP2/ERF family were screened to identify the repression motifs including L/F DLNL/F [53], R/KLFGV [54], and EDLL motif [55] using Clustal Omega [56].

\subsection{Three-Dimensional Protein Modeling and Molecular Docking via Protein Pocket Sites}

Three-dimensional structures related to four candidate TtAP2/ERF proteins from each of the recognized subfamilies including TtAP2/ERF-001 from DREB, TtAP2/ERF-036 from RAV, TtAP2/ERF-220 from AP2, and TtAP2/ERF-251 from ERF were created using iterative template-based fragment assembly simulations in the I-TASSER program [57]. The best models from I-TASSER were further improved by the 3Drefine program [58]. Afterward, the predicted structures were confirmed using a Ramachandran plot by measuring the backbone dihedral phi $(\phi)$ and psi $(\Psi)$ angles by the RAMPAGE program [59]. To predict the protein pockets and cavities, the refined structures of $T t A P 2 \mathrm{~s} / E R F$ s were subjected to the P2Rank program of PrankWeb software [60] and the CavityPlus tool [61], after which the structures were ultimately visualized via PyMOL (v. 2.4.1) [62].

\subsection{In Silico Expression Analysis of TtAP2/ERF Genes through RNA-Seq Data}

To evaluate the expression patterns of the TtAP2/ERF genes in different tissues (stem, leaf, grain, root, and spike) of durum wheat and in response to stress, 1 and $6 \mathrm{~h}$ after heat stress $\left(40{ }^{\circ} \mathrm{C}\right)$ and drought stress (20\% PEG6000), the available RNA-seq data of TtAP2s/ERFs were retrieved from project PRJEB22687 (SRA accession: SRP149116) from the Ensembl database. The fragments per 
kilobase of transcripts per million mapped reads (FPKM) expression values in five tissues as well as in response to stimuli (heat and drought) were obtained for the cultivar Svevo and then not expressed genes in all tissues and response to heat and drought stress were eliminated. Finally, $\log 2$ transformed to generate heatmaps using TBtools software (v. 1.0) [63].

\subsection{Plant Materials and Stress Treatments}

Triticum turgidum (durum wheat) seeds prepared from the Pasteur Biotechnology Institute of Tehran were disinfected by using $\mathrm{NaOCl}(0.5 \%)$ for $15 \mathrm{~min}$ and then put into glass dishes with Whatman filter paper, after which the dishes were incubated under a temperature of $25 \pm 2{ }^{\circ} \mathrm{C}$, a $16 \mathrm{~h}$ photoperiod (5000 lux), and $60 \pm 5 \%$ relative humidity. After seed germination, four-day-old seedlings were transplanted into aerated hydroponic culture tanks holding $30 \mathrm{~L}$ of a sterile half-strength Hoagland nutrient solution ( $\mathrm{pH}$ 6.0). Sixty seedlings were vertically fixed in each tank. After two weeks, the seedlings were exposed to drought and salinity stresses. Drought and salt stresses were imposed by the addition of PEG 6000 (polyethylene glycol, 15\% w/v) and $\mathrm{NaCl}(200 \mathrm{mM})$ to the nutrient solution, respectively. All treatments involved three biological replicates. Leaf samples were harvested after 6 and $24 \mathrm{~h}$ of stress treatments, and unstressed seedlings were used as control samples. Afterward, the collected plant materials were directly frozen in liquid nitrogen and stored at $-80{ }^{\circ} \mathrm{C}$ until extraction of their total RNA.

\subsection{RNA Extraction and RT-qPCR-Based Expression Assays of TtAP2s/ERFs}

Four wheat seedlings were pooled for RNA isolation. For extraction of the total RNA from the samples, TRIzol reagent (Invitrogen, Carlsbad, CA, USA) was used according to the manufacturer's recommendations. To eliminate genomic DNA, the extracted RNA was treated with DNase I (Thermo Fisher Scientific, Wilmington, MA, USA), after which the quality and quantity of the RNA samples were checked via an Implen N50 NanoPhotometer (Implen, Munich, Germany). Complementary DNA (cDNA) synthesized using an M-MULV reverse transcriptase kit (Thermo Fisher Scientific, Wilmington, MA, USA) according to the manufacturer's recommendations.

From the results achieved with the RNA-seq data re-analyzed in the previous section, 13 genes including six ERFs (TtAP2/ERF-009, TtAP2/ERF-025, TtAP2/ERF-070, TtAP2/ERF-104, TtAP2/ERF-107, and TtAP2/ERF-214), three DREBs (TtAP2/ERF-176, TtAP2/ERF-206, and TtAP2/ERF-227), two DRFs (TtAP2/ERF-185 and TtAP2/ERF-232), one AP2 (TtAP2/ERF-271), and one RAV (TtAP2/ERF-099) have been selected because of their potential involvement in drought and salinity stress responses, and their expression levels were further investigated in a qPCR analysis. The specific primers for the 13 candidate TtAP2s/ERFs and wheat Actin gene (AB181991.1), which served as a housekeeping gene for normalization of the RT-qPCR data, were designed using Primer3 online software [64] (Table S1). RT-qPCR was performed in $20 \mu \mathrm{L}$ reactions containing Maxima SYBR Green/ROX qPCR Master Mix (Thermo Scientific, Wilmington, MA, USA) according to the manufacturer's recommendations through a CFX96 RT-qPCR detection system (Bio-Rad, Hercules, CA, USA). Two-step thermal cycling was used for RT-qPCR, according to the company's instructions (initial activation step of 2 min at $50{ }^{\circ} \mathrm{C}$ and $10 \mathrm{~min}$ at $95^{\circ} \mathrm{C}$, followed by 40 cycles of $95^{\circ} \mathrm{C}$ for $15 \mathrm{sec}$ and $60{ }^{\circ} \mathrm{C}$ for $1 \mathrm{~min}$ ). The relative expression levels of the 13 candidate TtAP2/ERF genes were calculated using the $2^{-\Delta \Delta C T}$ method [65].

\section{Results}

\subsection{Identification of TtAP2/ERF Genes and Their Chromosomal Positions in the Durum Wheat Genome}

The deduced protein sequences of T. turgidum investigated via HMMER software led to the identification of 271 non-redundant putative TtAP2/ERF proteins (Table S2). The recognized genes were named according to their chromosomal location order in the A and/or B subgenomes of durum wheat as TtAP2/ERF-001 to TtAP2/ERF-271. There were 237 ERF (including 36 DREBs, 16 DREB-related factors (so-called DRFs), and 185 ERFs), 11 AP2, 10 RAV, and 13 SOLOIST (AP2/ERF-like) subfamily-related 
proteins in the recognized TtAP2/ERF gene family (Table S2). The putative proteins of TtAP2s/ERFs ranged from 80 (TtAP2/ERF-116) to 702 (TtAP2/ERF-102) amino acids in length, with molecular weights (MWs) ranging from 9.241 (TtAP2/ERF-116) to $153.177 \mathrm{kDa}$ (TtAP2/ERF-103) and theoretical isoelectric points (pI) ranging from 4.34 (TtAP2/ERF-149) to 12.03 (TtAP2/ERF-014), revealing an acidic nature of most of the putative TtAP2/ERF proteins ( $65.68 \%)$. Subcellular localization analysis based on CELLO results indicated that the majority of TtAP2s/ERFs ( 72\%) were localized in the nucleus, while $17.6 \%$ of TtAP2/ERF proteins were predicted to be localized in the chloroplast. Furthermore, $7.9,2.2$, and $0.4 \%$ of the proteins were also detected to be cytoplasmic, mitochondrial, and extracellular $T t A P 2 \mathrm{~s} / E R F \mathrm{~s}$, respectively (Figure 1A). Among the predicted $T t A P 2 \mathrm{~s} / E R F \mathrm{~s}, 136$ genes were mapped onto the durum wheat $B$ subgenome, and 135 genes were predicted to be localized onto the A subgenome (Figure 2). By carrying 27 genes, chromosome $6 \mathrm{~A}$ had the highest number of TtAP2s/ERFs, while chromosomes 2B, 2A, 5A, and 6B contained 25, 24, 24, and 23 genes, respectively. Chromosomes $1 \mathrm{~B}$ and $5 \mathrm{~B}$ also revealed substantial numbers of $T t A P 2 \mathrm{~s} / E R F \mathrm{~s}$, each carrying 21 genes, and chromosomes $7 \mathrm{~A}$ and $7 \mathrm{~B}$ had the minimum number of TtAP2s/ERFs (Figures $1 \mathrm{~B}$ and 2).

A
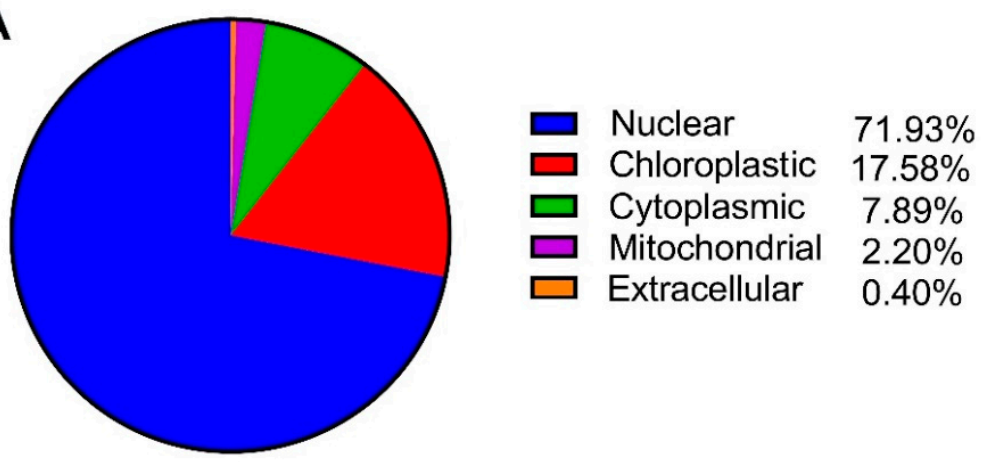

B

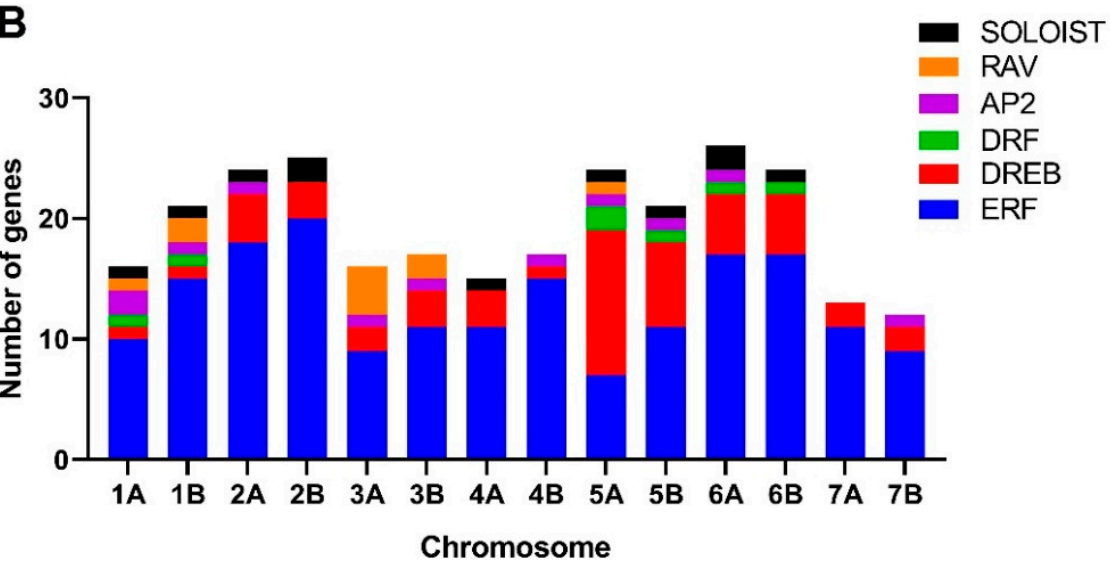

Figure 1. Subcellular localization of TtAP2/ERF proteins in durum wheat (A) and distribution of the TtAP2/ERF genes on the durum wheat chromosomes in both the A and B subgenomes (B).

\subsection{Conserved Amino Acid Residues in the DNA-Binding Domains of TtAP2/ERF Proteins}

To analyze the conservation of the TtAP2/ERF proteins from different subfamilies, their specific AP2 (SM000380) and B3 (SM01019) domains were aligned to generate specific sequence logos (Figure 3). AP2 is characterized by two conserved regions called YRG and RAYD. As regards the AP2 domain, the structure prediction revealed three $\beta$-sheets $(\beta 1, \beta 2$, and $\beta 3)$ and one $\alpha$-helix region that shared significant amino acid similarity within two YRG and RAYD elements (Figure 3). In particular, the amino acid residues 4G, 11G, 29L, 30G, 38A, 39A, 43D, and N57 were highly conserved among TtAP2s/ERFs. The structure of $\beta$-sheet 1 contained a conserved GVR element along with several sequences. Moreover, $\beta$-sheet 2 revealed a conserved EIR element with several substitutions, including $16 \mathrm{H}$ for $16 \mathrm{E}, 17 \mathrm{~V}$ for $17 \mathrm{I}$, and $18 \mathrm{~W}$ for $18 \mathrm{R}$. Our results suggested that the amino acid residues of EVR were present only 
in the ERF and DREB genes. In addition, $\beta$-sheet 3 revealed a conserved WLG element, which was highly conserved between T. durum and other species, such as Arabidopsis. Furthermore, the $\alpha$-helix structure contained a consensus sequence (positions 38-43) AAxA[YH]D, which is highly conserved among the RAYD elements (Figure 3). The conserved Ala45, an important residue for binding to GCC-box and DRE cis-elements $[14,66]$, was also fully conserved among all members of TtAP2s/ERFs. Moving to the B3 domain, characterized by seven $\beta$-sheets and two $\alpha$-helices (Figure 3), the amino acid residues 19P, 36L, 38D, 41G, 44W, 60G, 61W, 64F, 65V, 70L, 73G, 74D, and 78F were highly conserved among all TtAP2s/RAVs (Figure 3). The N-terminal region of TtAP2/RAV proteins contained an AP2 DNA-binding domain, while a highly conserved B3 domain existed in the C-terminal region. The B3 domain comprised seven $\beta$-sheets and two $\alpha$-helices (Figure 3).
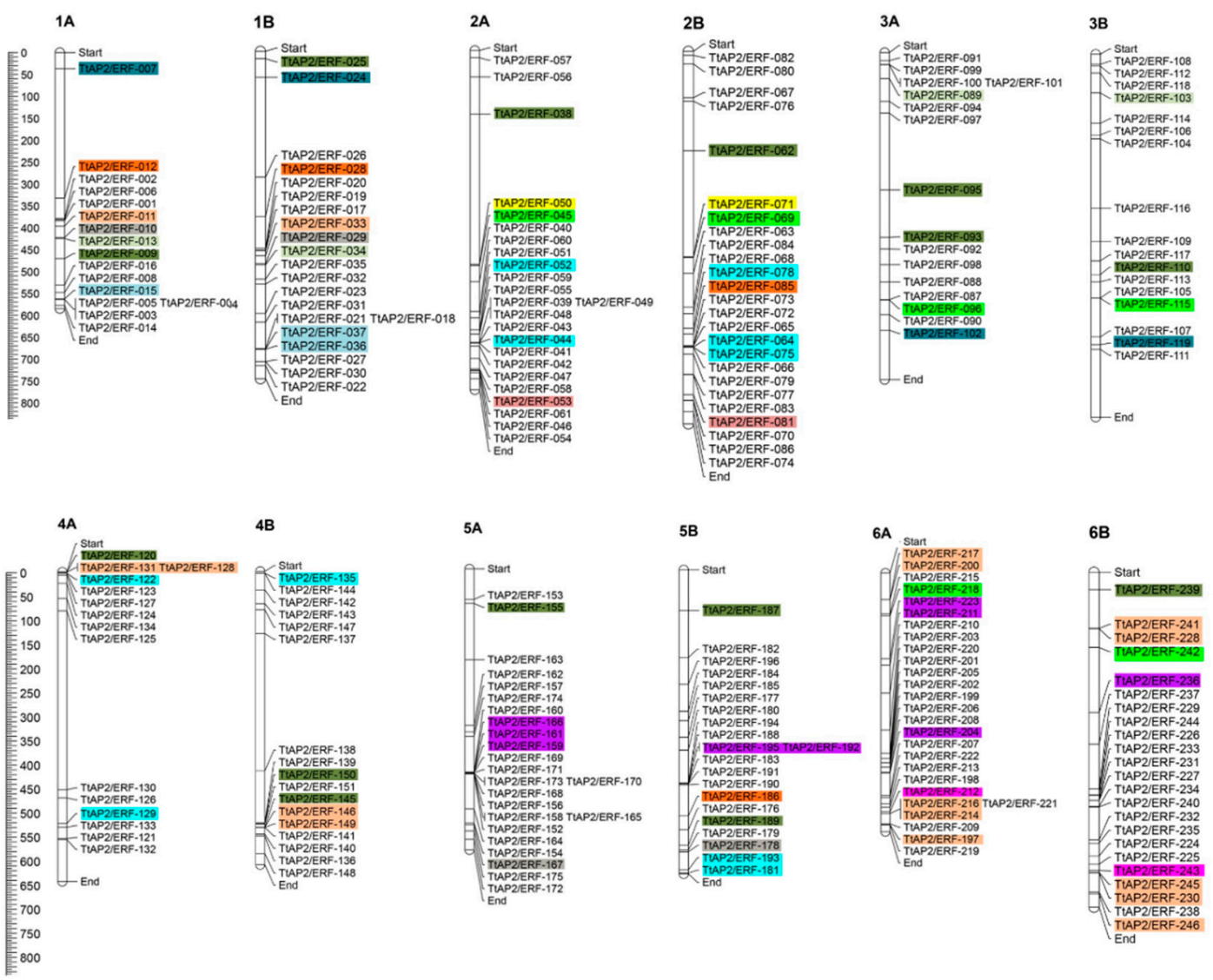

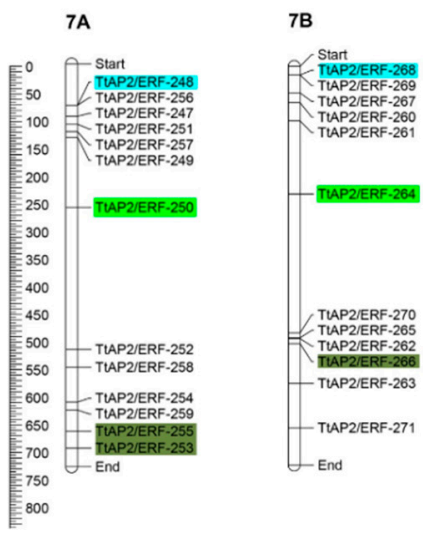

Figure 2. Chromosomal distribution of 271 non-redundant putative TtAP2/ERF genes predicted from the T. turgidum genome. The predicted duplicated pairs are highlighted in the same color. 


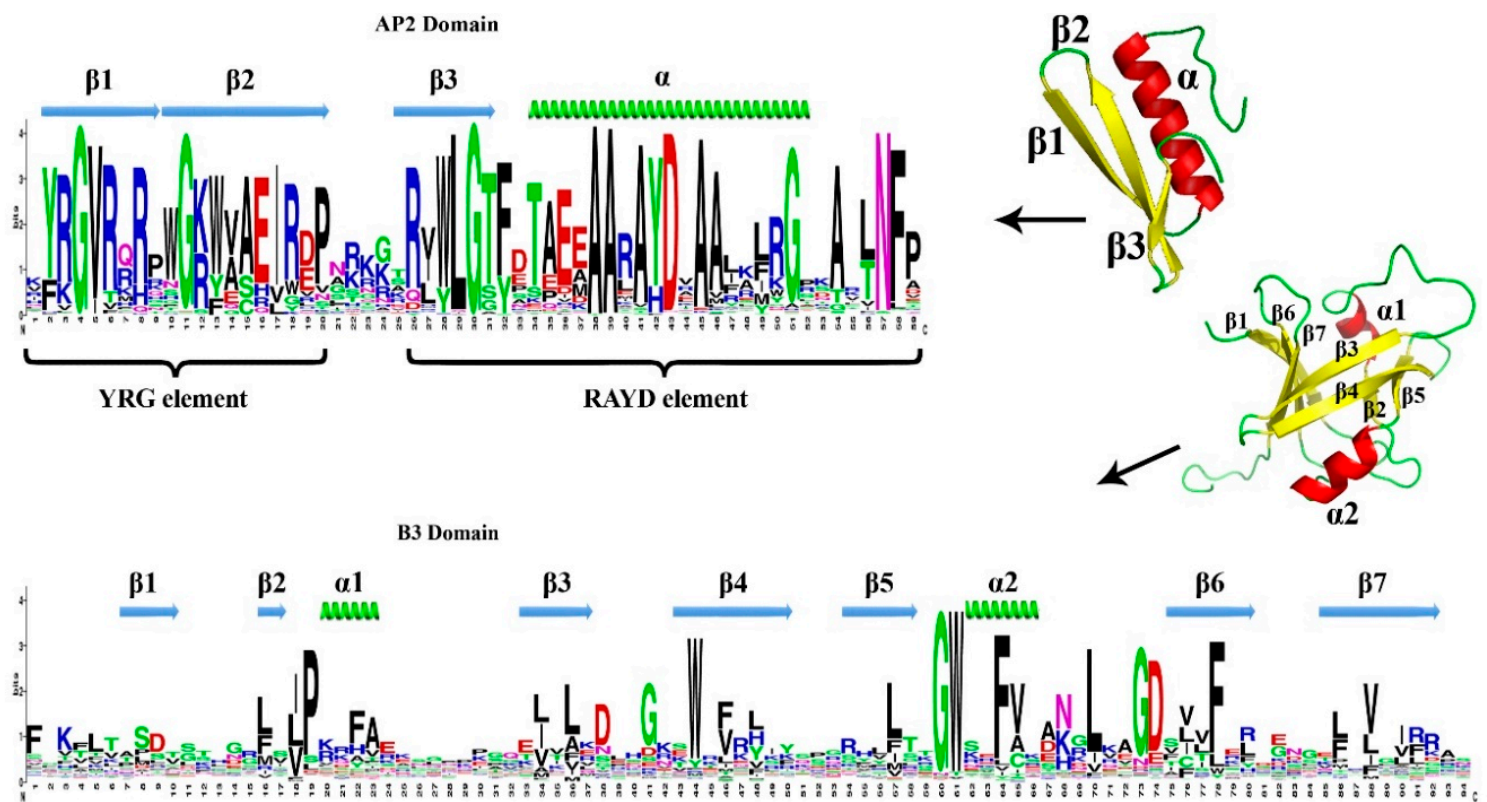

Figure 3. Molecular structure of the specific AP2 and B3 domains found in the 271 non-redundant putative TtAP2/ERF proteins predicted from the T. turgidum genome. The abundance of each amino acid is represented by a sequence logo and the secondary and the tertiary structure of each of the domains has been predicted using the PDB database and the I-TASSER program.

\subsection{Phylogenetic Relationships and Conserved Motifs}

Phylogenetic analyses are necessary to understand the evolutionary history of plant lineages. Phylogenetic analysis revealed the clustering of all TtAP2s/ERFs into 19 different groups; clades I to $\mathrm{X}$ and XIV to XVI contained multiple kinds of ERFs, clades XI and XII comprised DREBs, clade XIII contained DREB-related factors (DRFs), clade XVII comprised RAV proteins, clade XVIII contained AP2s, and, lastly, clade XIX contained SOLOIST members (Figure S1). Based on the conserved protein motifs, 15 motifs (Figure S1) were identified of which five of them (motifs 1, 2, 3, 4, and 10) represented the AP2 domain in the TtAP2/ERF structure (Figure S1 and Table S3). Motif 2 and motif 1 contained the important parts of the AP2 domain, the YRG and RAYD elements, respectively, and motifs 4 and 3 were related to the $\mathrm{N}$-terminal region of YRG and the C-terminal region of RAYD elements, respectively. The motif combination comprising motif 4 , motif 2 , motif 1 , and motif 3 was related to the AP2 domain catalytic activity and was predicted to exist in approximately all TtAP2s/ERFs, except for the XVII, XVIII, and XIX clade-related proteins that contained two or three AP2 catalytic motifs. Motif 8 and motif 14 were present in the B3 domain in all RAV-related proteins (Figure S1). The AP2/ERF proteins belonging to the same groups also had several conserved motifs beyond the AP2 domain region. For instance, motifs 11,14, and 8 were shared by all members in the RAV subfamily, and motifs 4, 9, and 11 were also present in AP2 subfamily-related proteins (Figure S1). The predicted SOLOIST proteins had a modified combination of the AP2 protein motifs that were in accordance with the reason underlying their nomenclature. Additionally, motif 5 and motif 6 were predicted only in some members of ERF proteins in clade II, and motif 12 and motif 13 existed only in ERFs from clades $\mathrm{V}$ and $\mathrm{XV}$, respectively. Hence, the motif structures are somewhat conserved in each AP2/ERF clade, which is in line with the conserved and specific functions of the proteins in these clusters.

The evolutionary relationships of the TtAP2/ERF genes were further assayed by phylogenetic analysis of all the TtAP2/ERF members and the rice and Arabidopsis AP2/ERF gene family members. According to the results, the $A P 2 / E R F$ genes could be clustered into nine major groups, six ERF clades, a RAV clade, an AP2/AP2-Like clade, and an ERF-Like clade, based on their domain structure as described above and on their evolutionary history (Figure 4). With respect to the classification 
criteria in Arabidopsis and rice [67], the ERFs could be further divided into DREB and ERF subfamilies. The AP2 group could also be divided into two AP2-like (SOLOIST) and AP2 subclades. In addition, the bootstrapping magnitudes of the nodes of this phylogenetic tree were substantial in the ERF clades, suggesting that the cellular function of these proteins from various plant species was relatively evolutionarily conserved.

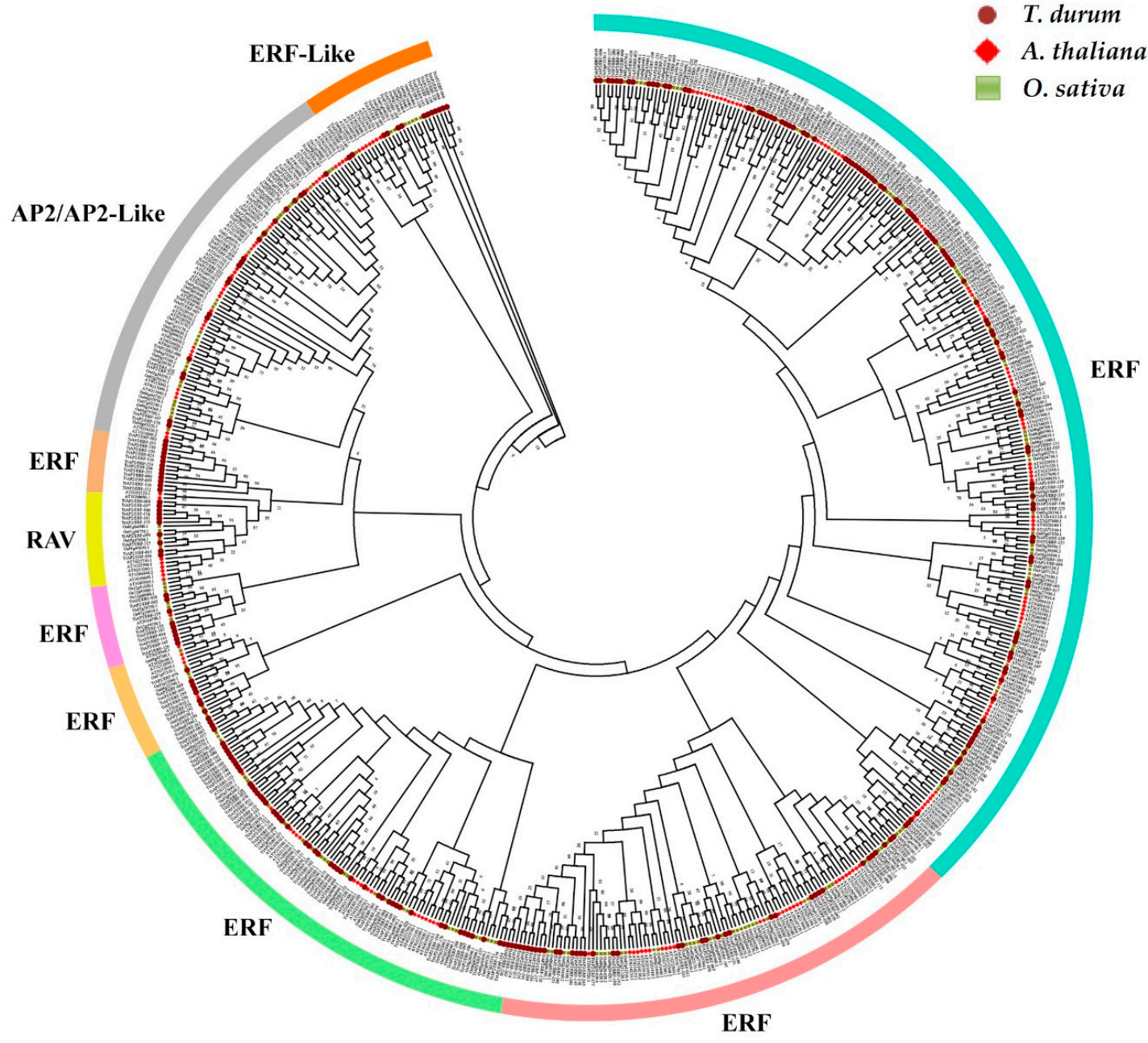

Figure 4. Phylogenetic analysis of AP2/ERF proteins from durum wheat, rice, and Arabidopsis using MEGA 6 software based on the NJ method.

\subsection{Gene Ontology Annotations}

Evaluation of the biological processes mediated by TtAP2s/ERFs indicated that the same percentage of proteins were involved in cellular nitrogen compound metabolic processes $(\sim 19 \%)$ and biosynthetic processes ( $19 \%)$. Among the TtAP2/ERF family proteins, $\sim 18$ and $17.6 \%$ of members showed potential involvement in signal transduction and response to stimuli, respectively, during the durum wheat life cycle (Figure 5). Furthermore, the TtAP2/ERF proteins were found to be involved in the regulation of multiple aspects of developmental processes, such as anatomical structure development $(\sim 15 \%)$, regulation of growth $(\sim 4 \%)$, embryo development $(\sim 2 \%)$, and cell differentiation $(\sim 1 \%)$. Moreover, the involvement of $T t A P 2 \mathrm{~s} / E R F \mathrm{~s}$ in reproduction $(\sim 8 \%)$, lipid metabolic processes $(\sim 2 \%)$, and aging control $(\sim 2 \%)$ was predicted through gene ontology enrichment analysis. In the context of molecular functions, as expected the $96 \%$ of the TtAP2/ERFs showed GO IDs related to nucleic-acid binding activity (Figure 5). The molecular processes regulated by TtAP2/ERF proteins significantly demonstrated that most of these proteins exert sequence-specific DNA-binding transcription factor activity. The potential 
involvement of several TtAP2/ERF proteins in protein binding ( $2 \%)$ and ion binding ( $2 \%)$ were also predicted to be molecular functions in the cell.
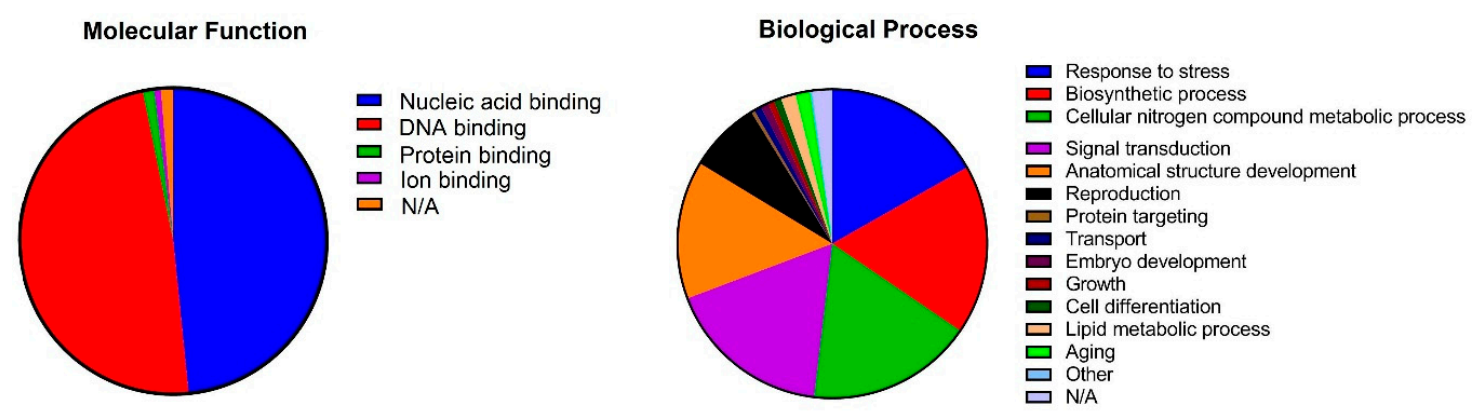

Figure 5. Molecular functions and biological processes of members of the TtAP2/ERF family based on gene ontology (GO) analysis.

\subsection{Identification of Duplicated Gene Pairs with Estimation of Ka/Ks Ratios}

Seventy duplicated gene pairs clustering into the 13 groups were identified in the TtAP2/ERF family based of phylogenetic results, and the same duplicated regions between paralogous pairs were found (Figure 2). Among the duplicated clades, clades 10, 1, and 3 revealed substantial numbers of duplication events, with 29, 11, and 8 gene pairs, respectively (Table S4). The highest number of duplicated gene pairs was observed on chromosomes $6 \mathrm{~A}$ and $6 \mathrm{~B}$, with nine duplicated gene pairs. In this study, the $K a / K s$ values varied from 0.0035 to 0.9936 . Several of the duplicated gene pair blocks, such as TtAP2/ERF-036-TtAP2/ERF-037 and TtAP2/ERF-064-TtAP2/ERF-075, were collinear based on analysis of intra-species synteny. All the duplicated gene groups in the TtAP2/ERF gene family of durum wheat have been influenced by intense purifying selection because of the estimated $\mathrm{Ka} / \mathrm{Ks}$ values $<1$. Based on phylogenetic analysis, annotations, and motif structures, it was revealed that the genes in a duplicated pair can be functionally conserved. For instance, the duplicated pairs TtAP2/ERF-010-TtAP2/ERF-029 and TtAP2/ERF-167-TtAP2/ERF-178 were related to the phylogenetic clade XIX and the SOLOIST proteins, which showed similar motif patterns (Figure S1 and Table S4).

\subsection{Homology Modeling of TtAP2/ERF Proteins and Docking Assays of Their Pocket Sites}

Three-dimensional models of four candidate TtAP2/ERF proteins (one member from each of the DREB (TtAP2/ERF-001), ERF (TtAP2/ERF-251), RAV (TtAP2/ERF-036), and AP2 (TtAP2/ERF-222) subfamilies) were assembled using the PDB database and the I-TASSER program. The 3D structures showed the presence of the conserved AP2 domain (approximately 60-70 amino acids) within all the TtAP2s/ERFs; the domain had a typical three-dimensional frame comprising three antiparallel $\beta$-sheets followed by a parallel $\alpha$-helix (Figure 6). The N-terminal region of the TtRAV protein contained one AP2 domain, along with a highly conserved B3 domain that existed in the C-terminal region and that was comprised of seven $\beta$-sheets and two $\alpha$-helixes (Figure 6).

Topographic features of TtAP2/ERF proteins were assessed through the P2Rank program; the major pockets of which are presented here as multiple colored regions (Figure 6). Three, six, four, and five major pockets were predicted as binding regions/active sites in the candidate proteins from the DREB, ERF, RAV, and AP2 clusters, respectively. The amino acid residues present in the pocket sites of the TtAP2/ERF proteins partially differed in each subfamily, although $\mathrm{Mg}$ or Ca ions were present in the center of the active sites of all the predicted TtAP2/ERF protein models. SER, GLY, HIS, PRO, GLU, TYR, and ARG amino acids were identified as the important binding residues in the predicted pocket sites of the DREB and ERF proteins (Figure 6); these findings strongly indicate the potential roles of these proteins in the response to stress as well as growth and development modification in durum wheat. Investigations of the predicted pocket sites of RAV and AP2 family-related proteins also demonstrated some parts rich in the stress-responsive residues GLY, PRO, HIS, and SER as well 
as growth-regulating amino acids LEU, VAL, GLU, ALA, and TYR (Figure 6). Based on our results, the important amino acids found in the pocket sites of all the candidate TtAP2/ERF proteins may indicate the importance of these residues in the positioning onto the DNA molecule and, ultimately, the cellular function associated with various developmental and defensive processes.
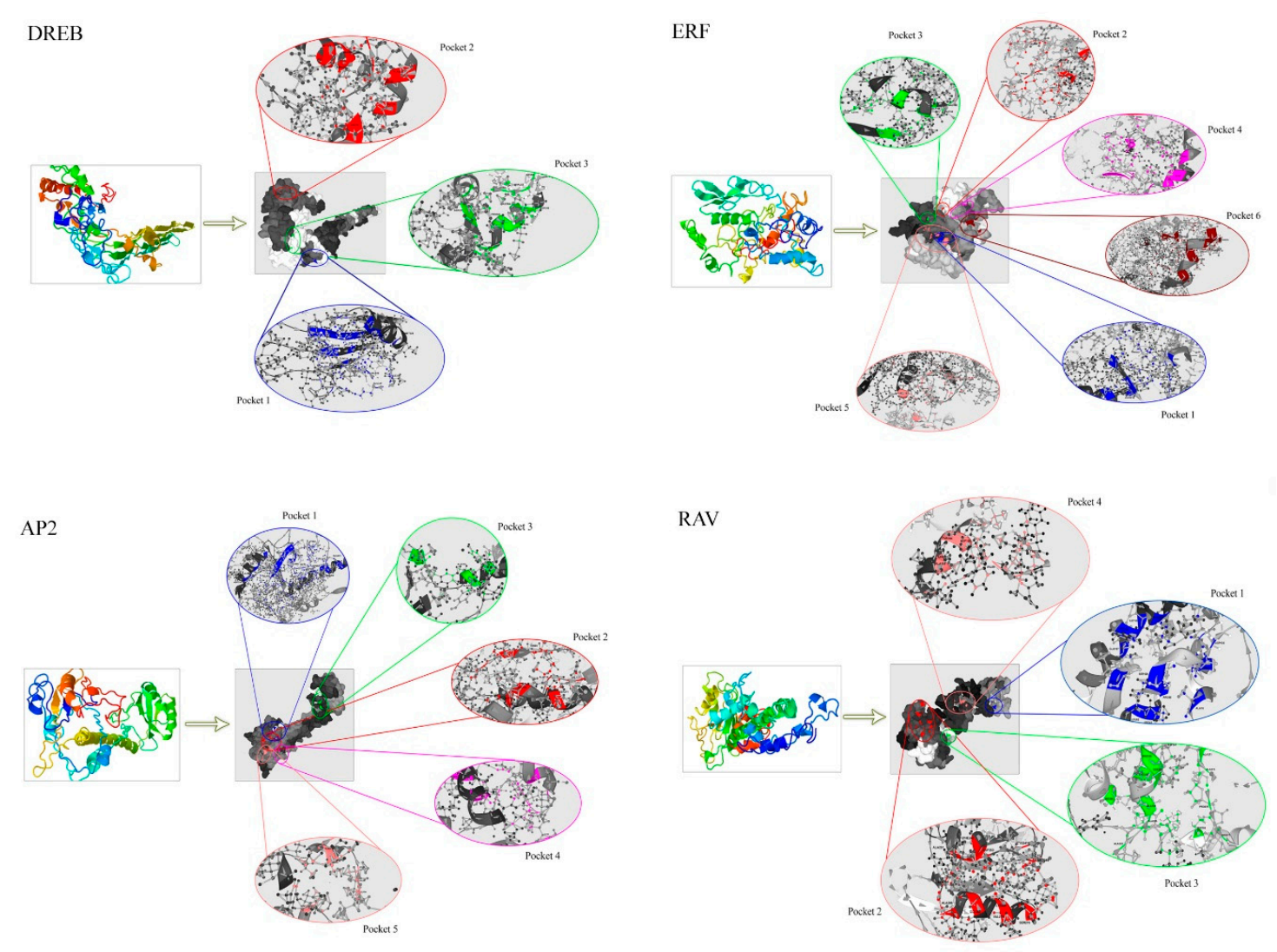

Figure 6. Predicted 3D structure of candidate TtAP2/ERF proteins in durum wheat. Docking analysis of the major protein pocket sites was also performed before each 3D model was constructed.

\subsection{Assay of TtAP2s/ERFs Expression in Multiple Tissues and under Abiotic Stimuli via RNA-Seq}

The expression levels of the TtAP2/ERF genes were evaluated under normal growth conditions in multiple tissues as well as during stress conditions via available RNA-seq datasets. The results revealed that TtAP2/ERF genes have tissue-specific expression patterns (Figure 7A). According to the transcript levels, TtAP2s/ERFs could be divided into different expression groups that contained genes preferentially expressed in all or one of the following tissues: grain, root, leaf, spike, and stem tissues (Figure 7A). The expression levels related to the seven TtAP2/ERF genes were significantly high in all five tissues, including the expression of five and two genes from the ERF and DRF subfamilies, respectively, suggesting control of a broad set of genes at the transcriptional level. According to the results, it was also found that $A P 2 / E R F$ genes are less expressed in spike than other tissues (Figure 7A). Seven ERF genes (TtAP2/ERF-042, TtAP2/ERF-079, TtAP2/ERF-152, TtAP2/ERF-218, TtAP2/ERF-242, TtAP2/ERF-250, and TtAP2/ERF-264), and two DREB genes (TtAP2/ERF-013 and TtAP2/ERF-034) were specifically expressed in durum wheat grain tissue. The largest tissue-specific expression group included genes that were significantly expressed in the root and stem tissues (Figure 7A). 
A

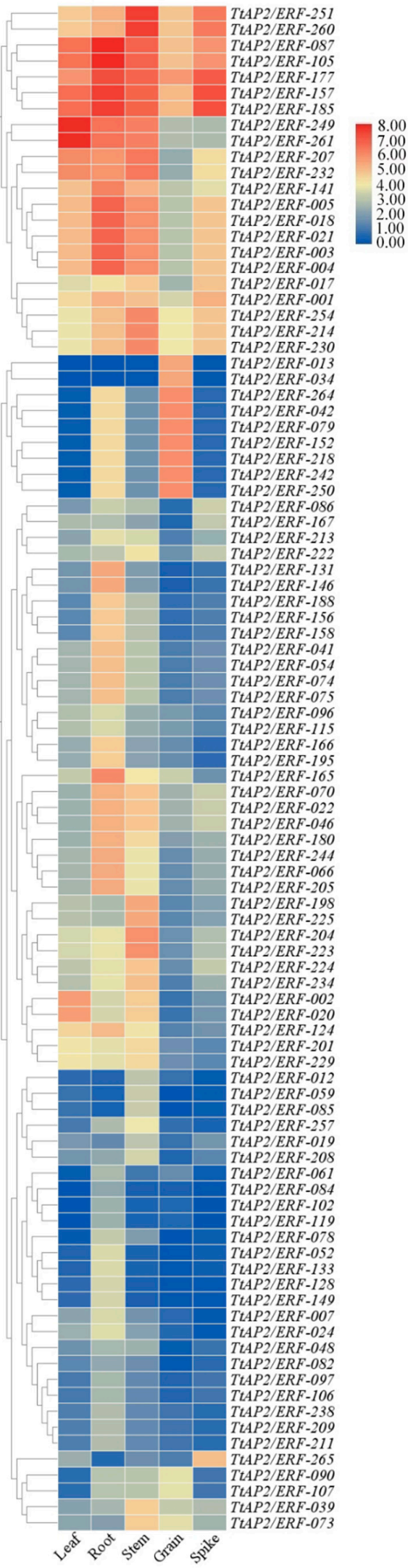

B

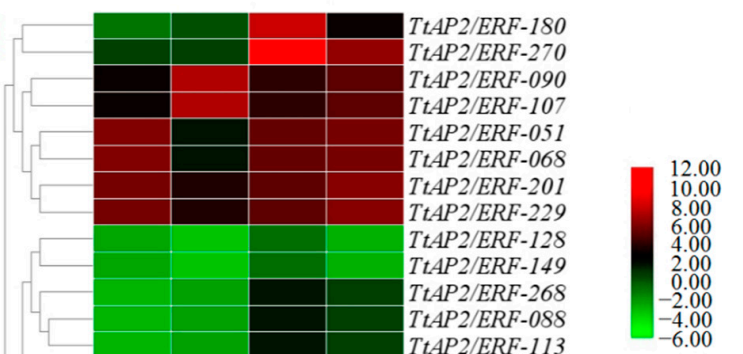

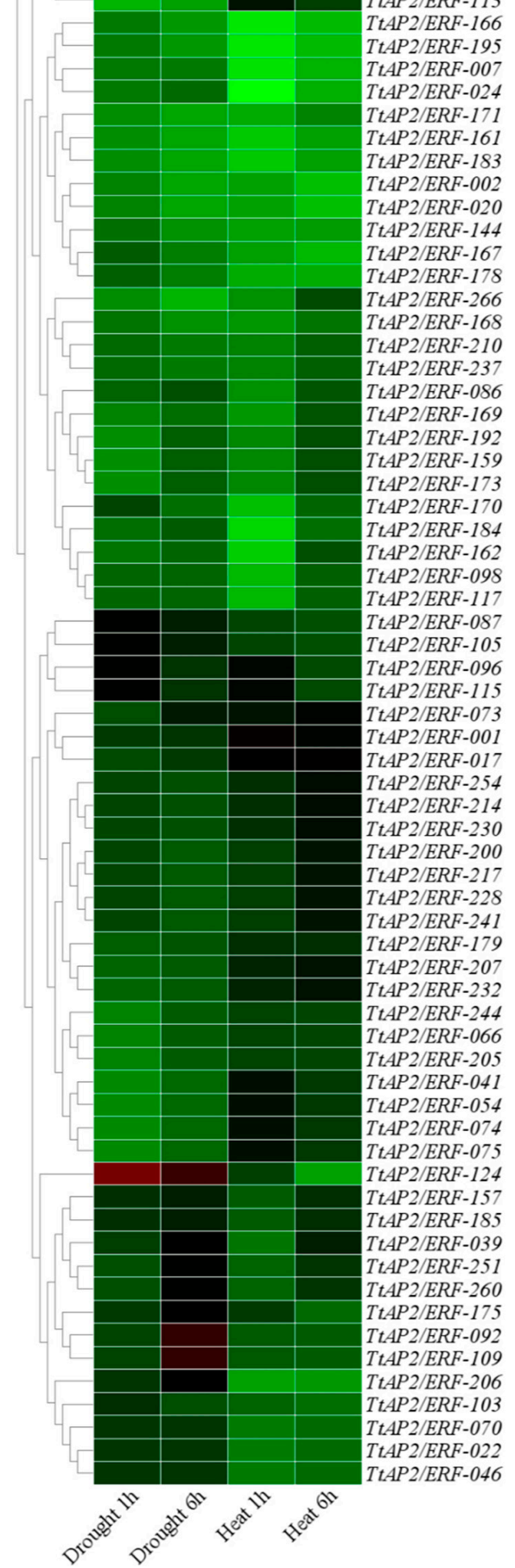

Figure 7. Expression heatmaps of putative TtAP2/ERF genes in five different tissues (namely leaf, root, stem, grain, and spike) of durum wheat (A) and under drought (1 and $6 \mathrm{~h}$ ) and heat stresses (1 and $6 \mathrm{~h})$ conditions (B). 
RNA-seq data were also employed to further verify the expression of the identified TtAP2/ERF genes after $1 \mathrm{~h}$ and $6 \mathrm{~h}$ of heat and drought stresses in leaf tissues of durum wheat. A total of six TtAP2/ERF genes from the ERF subfamily (TtAP2/ERF-090, TtAP2/ERF-107, TtAP2/ERF-051, TtAP2/ERF-068, TtAP2/ERF-201, and TtAP2/ERF-229) were significantly upregulated under all stimuli (Figure $7 \mathrm{~B}$ ). Based on the results, most genes were downregulated in response to drought and heat stresses. The mRNA levels of three genes, such as TtAP2/ERF-124 belonging to the DREB subfamily, TtAP2/ERF-124 and TtAP2/ERF-092 from the ERF subfamily increased only in response to drought conditions and could be considered drought-responsible TtAP2/ERF genes. Furthermore, the transcript levels of two TtAP2/ERF genes, including TtAP2/ERF-180 and TtAP2/ERF-270 from the ERF gene subfamily, were significantly upregulated only after heat stress exposure, suggesting their involvement in the heat response. However, some DREBs were downregulated in response to stress, suggesting an acclimation response involving members of this subfamily, which may assist in normalizing cell osmotic potential and, eventually, durum wheat resistance to stimuli. It should be mentioned that the response to stress by the ERF protein-encoding genes was considerable in comparison with that of the other related subfamily genes. Furthermore, the transcript levels of the genes encoding DREB proteins and ERF proteins were high in response to stimuli.

\subsection{Identification Repression Motifs in TtAP2/ERFs}

Protein sequences of $T t A P 2 / E R F$ genes were screened to identify the repression motifs, [R/K]LFGV, FDLNLPP, and EDLL. The results showed that nine genes belonging to the RAV subfamily contain the [R/K]LFGV motif, most of which (except for TtAP2/ERF-117) were not induced in response to drought and heat stress (Figure 8A). Additionally, four proteins belonging to ERF subfamily had a FDLNLPP motif, and two genes of them, TtAP2/ERF-054 and TtAP2/ERF-074, were involved in early response to drought and heat stress (Figure 8B). Besides, motif EDLL was identified in six ERF proteins that were not expressed under drought and heat stress (Figure 8C).

\subsection{Expression Levels of TtAP2s/ERFs after Stimulus Exposure According to RT-qPCR}

From the results achieved with the RNA-seq data re-analyzed in the previous section, 13 genes have been selected because of their potential involvement in drought and salinity stresses responses, and their expression levels were further investigated in a qPCR analysis. Thirteen TtAP2s/ERFs (including six ERFs, three DREBs, two $D R F \mathrm{~s}$, one $A P 2$, and one $R A V$ ) were selected for further assays of their potential in coping with drought and salinity stresses in durum wheat leaf tissue. The TtAP2/ERF genes belonging to the DREB gene subfamily (including TtAP2/ERF-176, TtAP2/ERF-206, and TtAP2/ERF-227) were markedly induced under both drought-stress and salinity-stress conditions compared with those in the control sample (Figure 9). The expression levels of the candidate DRF genes (including TtAP2/ERF-185 and TtAP2/ERF-232) also increased in response to each stimulus and confirmed the RNA-seq results; TtAP2/ERF-185 was significantly upregulated in response to salinity-stress conditions, but the transcript levels of TtAP2/ERF-232 increased under drought stress exposure compared with the control conditions. The transcript levels of a candidate $R A V$ gene, $T t A P 2 / E R F-099$, tended to increase in response to salinity stress over time, but after an approximately three-fold increase after the initial drought stress imposition, the levels significantly decreased in response to the long-term stress compared to those under the control conditions (Figure 9). In contrast to the RNA-seq results, the expression assay of the RAV gene TtAP2/ERF-099 and AP2 clade-related gene TtAP2/ERF-271 revealed a considerable increase in expression in response to each stimulus. Some candidate TtAP2s/ERFs belonging to the ERF group, such as TtAP2/ERF-025 and TtAP2/ERF-107, were upregulated with increasing drought stress, while significant decreases were found after long-term salinity exposure in comparison with the results of the control sample. The transcript levels of two ERF genes, TtAP2/ERF-009 and TtAP2/ERF-070, substantially increased over time in response to all stimuli, suggesting that they have critical roles in stress adaptation (Figure 9). The mRNA levels of TtAP2/ERF-104 and TtAP2/ERF-214 significantly decreased during the early drought and salinity stress 
treatments, respectively; however, their expression levels increased after $24 \mathrm{~h}$ of drought and salinity stress. Overall, our findings revealed that most of the selected AP2/ERF genes are involved in the response to salinity and drought stress, although their expression levels varied according to the type and duration of stress.

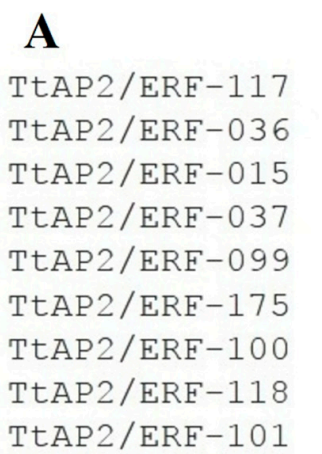

B

TtAP 2 / ERE-054

TtAP2/ERF-074

TtAP2/ERE-042

TtAP2/ERF-079

C

TtAP2/ERF-026

TtAP 2/ERF-121

TtAP2/ERF-136

TtAP2/ERF-153

TtAP2 / ERF-122

TtAP 2/ERF-135

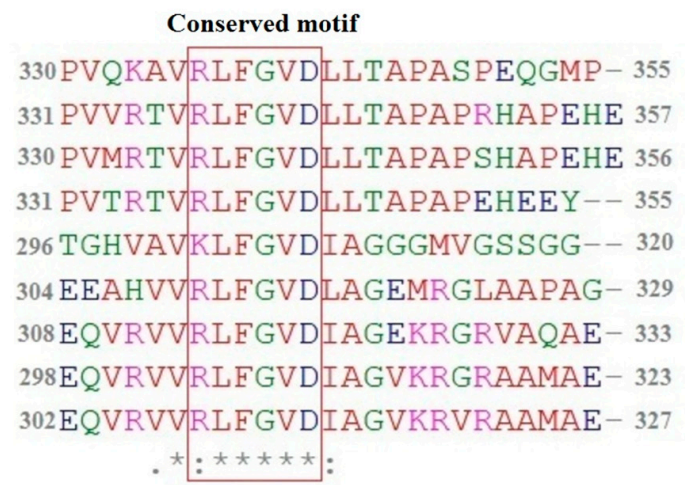

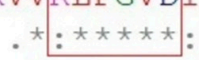
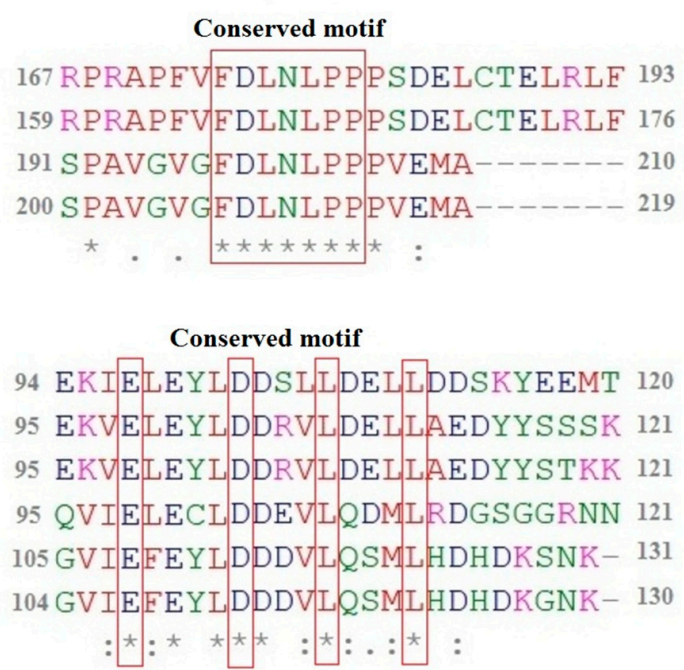
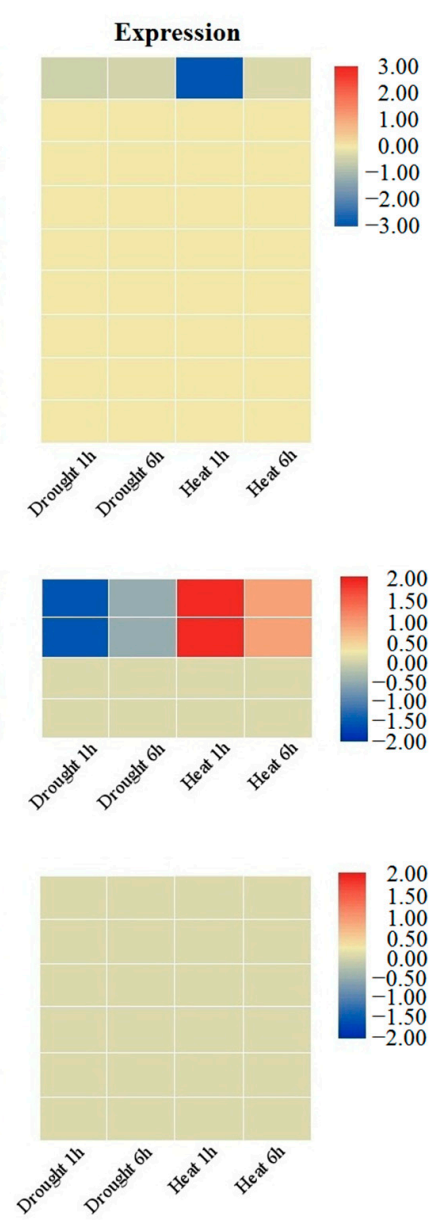

Figure 8. List of TtAP2/ERF genes contained repressor motifs with their expression. List of genes containing $[\mathrm{R} / \mathrm{K}] \mathrm{LFGV}$ motif (A), FDLNLPP motif (B), and EDLL motif (C). 

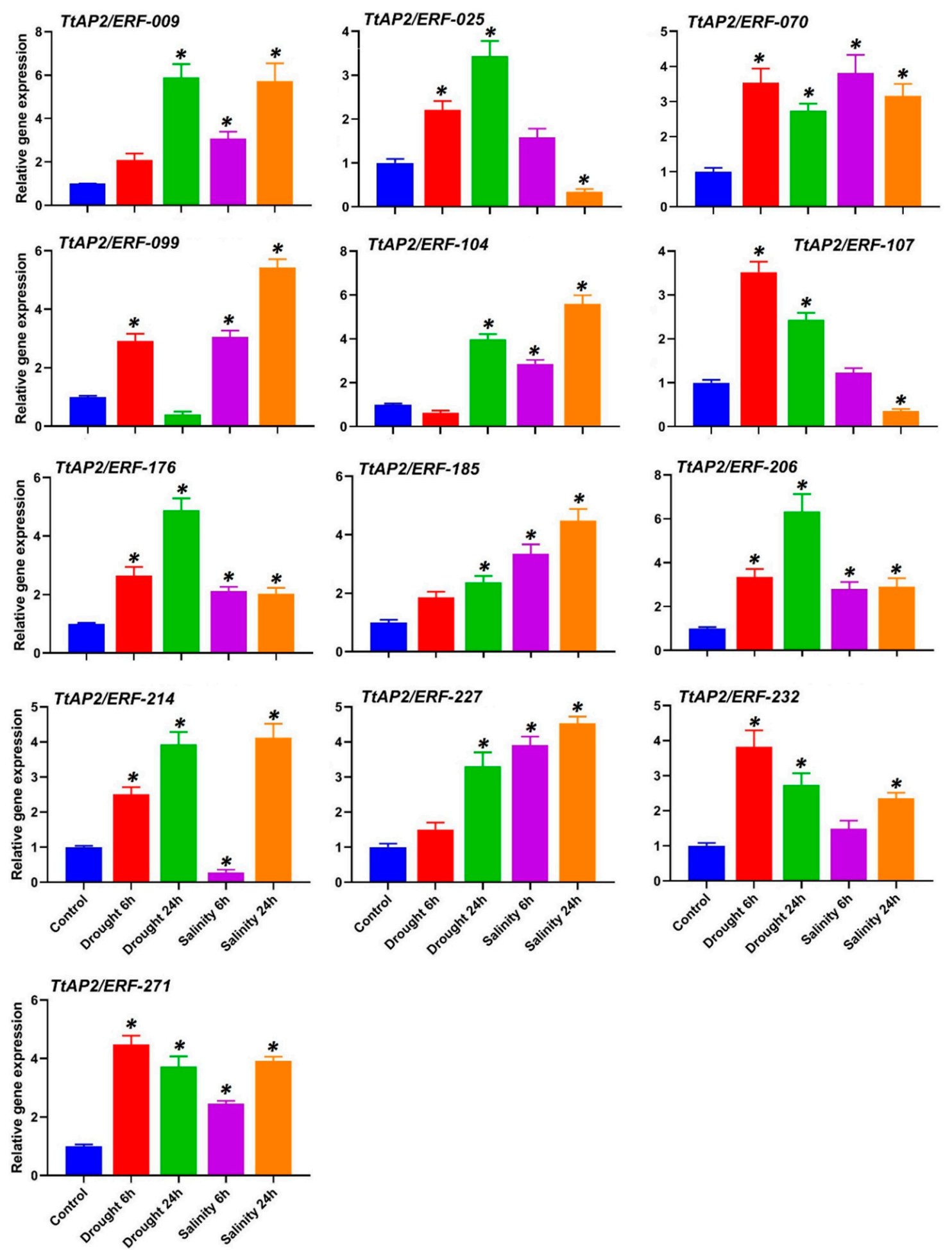

Figure 9. Relative expression levels of 13 candidate TtAP2/ERF genes after drought and $\mathrm{NaCl}$ stress. The values are given as the means \pm SDs of three biological replicates, and the * above the bars show a significant difference between the applied treatments and the control at $p<0.05$ (according to Student's $t$-test).

\section{Discussion}

Systematic evaluation of the diverse gene/protein families involved in the regulation of multiple developmental processes and stimuli can provide insights into the critical regulatory mechanisms 
of different plant genomes. A vast number of previously published reports have shown extensive involvement of $A P 2 / E R F$ transcription factors in plant growth and development and critical cellular metabolism processes $[15,68,69]$. In the present study, 271 AP2/ERF genes were identified in the durum wheat genome, the number of which was lower than that reported in Brassica napus [14], with 321 members; however, 271 was greater than the 171 AP2/ERF genes in Setaria italica [19], the 141 genes identified in B. distachyon [34], the 122 genes in Arabidopsis [67], the 139 genes in rice [67], and the 117 genes in bread wheat [12]. Based on this, it could be hypothesized that the number of genes is directly correlated with the genome size and ploidy level in plants. In addition to ploidy level and genome size, various distributions of the $A P 2 / E R F$ genes in durum wheat compared to the other cereal species may be determined by gene duplication events to establish certain biological roles, such as resistance to stimuli. The extensive variation predicted for TtAP2/ERF gene lengths and the physicochemical properties of these proteins may suggest that the durum wheat genome underwent a significant evolutionary change [70]. The majority of $T t A P 2 \mathrm{~s} / E R F \mathrm{~s}$ are predicted to be nuclear proteins, suggesting their critical roles in transcriptional adjustment and signal transduction [71].

Several credible pairs of homologous AP2/ERF proteins with the same cellular functions were distinguished in this study because of the high bootstrap values predicted among some internal branches of the phylogenetic constructed tree. Identification of cellular functions according to phylogenetic relationships is frequently reported as a rational systematic approach for exploration of orthologous genes in various plant species $[19,72,73]$. Accordingly, the TtAP2s/ERFs belonging to each subfamily in durum wheat revealed similar motif structures and regulatory roles compared with those of their orthologs from other plant species, such as Arabidopsis [74] and B. distachyon [34]. In the current study, some conserved motifs in TtAP2/ERF proteins were predicted to lie in the regions outside the DNA-binding domain; moreover, it should be mentioned that both the factors affecting transcriptional modification and nuclear localization-related domains can be found in these regions [75]. The predicted similarity in motif structures may result from recent segregation events across the durum wheat genome and its evolutionary process [76]. Some close association of TtAP2/ERF subfamily members, especially $D R F, D R E B$, and $R A V$ members, with their related counterparts from the Arabidopsis and rice genomes may reveal remarkable similarity in terms of expression and regulatory functions [19].

Gene duplication events have substantial roles in the evolutionary expansion of gene families in terms of the formation of novel genes, which supports organisms adapting to diverse conditions [77]. Tandem, whole-genome, or segmental duplications constitute the proposed models of gene duplications in plant species [77]. In our study, we identified 13 groups of duplicated genes in TtAP2/ERF genes dispersed in segmentally duplicated blocks, indicating that the expansion of the TAAP2/ERF gene family may be the result of a high number of duplication events [77]. Furthermore, many of the duplicated gene pair blocks were collinear, suggesting that these duplication events may be derived from chromosome segmentation events or large-scale duplication/triplication events [78]. Ka/Ks values are known as an index for selection pressure [77]. In the current study, the mean $\mathrm{Ka} / \mathrm{Ks}$ value of duplicated TtAP2/ERF gene pairs was predicted to be less than 1 (0.4773), strongly supporting that the TtAP2/ERF gene family survived extreme purifying selection pressure by substitution elimination and high selective pressure by natural selection throughout the evolutionary process $[77,79]$. Genes with conserved functions and/or pseudogenization may be generated by purifying selection [80].

Accordingly, molecular modeling suggested that all the predicted structures of proteins were highly consistent, which may provide an elementary reason for understanding the molecular functions of TtAP2/ERF proteins. Our findings were consistent with the results of previous studies on the 3D homology of AP2/ERF proteins [81]. The AP2 subfamily members contain two AP2 domains separated by a linker sequence of approximately 25 amino acids, which is responsible for the positioning of the DNA-binding domains [82] and is well illustrated in the TtAP2 protein structure (Figure 6). Previous studies of the AP2 domain demonstrated the presence of two important regions, namely, RAYD and YRG [19], which were also found in durum wheat TtAP2s/ERFs in the present study. The YRG region includes 20 amino acids in the $\beta 1$ sheet of the AP2 domain, which has been shown to 
play a critical role in establishing direct contact with the DNA molecule [83]. Conversely, the RAYD region contains approximately 40 amino acids in the $\alpha$-helix region and is involved in protein-protein interactions (see Figure 3). Moreover, various reports have also indicated that the RAYD region is required in DNA binding for interactions of the hydrophobic surface of the $\alpha$-helix with the DNA major groove [83].

Protein surface pockets and interior cavities are considered the topological and geometric characteristics of protein structures that are essential for DNA-protein interactions and enzymatic activities [84]. The interaction specificity of proteins is altered through the dynamics of protein-binding pockets, which contribute to the structural flexibility of the binding process [85]. As such, changes in the surface pocket topography of the modeled TtAP2s/ERFs can contribute to the functional plasticity of TtAP2s/ERFs. The high amount of the GLY and PRO amino acids in the pocket sites of the modeled proteins suggest that the amino acid composition (along with the genetic aspects) work to reduce the environmental effects on protein structure and function [86]. It has been reported that GLY/PRO-rich proteins have important roles in plants in response to various abiotic and biotic stress situations by altering the expression of other genes [87]. The presence of several important amino acids, such as SER, LEU, VAL, and PRO, in the protein pocket regions can significantly alter various protein functions in response to adverse conditions $[88,89]$. Additionally, the CYS and LYS residues observed in pocket 4 and pocket 6 of the ERF protein, respectively, may suggest an important role of these proteins in sulfur metabolism and starch biosynthesis [90]. Furthermore, the cavity region in the TtRAV protein also revealed CYS residues, suggesting a potential role of $T t A P 2 \mathrm{~s} / E R F \mathrm{~s}$ of these clades in the modulation of sulfur metabolism through regulation of the sulfotransferases [91]. Prediction of the TRP and GLU residues in all of the modeled TtAP2/ERF active sites also demonstrates their important potential involvement in immunity during the hypersensitive response to hemibiotrophs [92]. Our results also suggested that the composition of amino acids in the TtAP2/ERF protein domains was extremely conserved and that some amino acid variations may amend the classification of the genes.

In the present study, in silico expression analysis of all 271 TtAP2/ERF genes in five major tissues via RNA-seq datasets demonstrated differential expression of these genes. Expression profiling of tissue-specific $T t A P 2 \mathrm{~s} / E R F \mathrm{~s}$ can facilitate the combined use of these genes in transcriptional regulation in various tissues and/or organs, while ubiquitously transcribed members can alter the transcription of many genes [21,93]. Tissue-specific expression heatmaps can provide important information concerning the overexpression of TtAP2s/ERFs in multiple tissues to provide information concerning resistance to stimuli in durum wheat. These changes in the magnitude of expression of transcripts encoding $A P 2 / E R F$ s that participate in signaling and protein targeting mechanisms suggest that the pathway of these TFs involves highly coordinated interactions of both development- and defense-related signals [5,7]. Regarding the results, most of the genes with a tendency to be expressed in specific tissues are members of the $E R F$ and $D R E B$ subfamilies, which may reveal the important roles of these genes in the regulation of development and the integration of multiple organs and/or tissues [68,69]. The in silico transcription assay of the AP2/ERF gene family from durum wheat can provide new empirical transcriptome references for improving Triticeae agronomic properties [70] and insights into transcriptional programming during multiple situations.

It has been reported that TtAP2/ERF proteins play important roles in mediating signal transduction pathways and responses to various stresses in durum wheat, and this has been reported by several researchers $[19,34,94]$. Based on our RNA-seq analysis results, a total of 83 TtAP2s/ERFs were up- or downregulated under stress, indicating that they are largely involved in the response to stimuli. Genes of the ERF subfamily were more highly expressed than were AP2 genes in response to drought and salinity stresses. For instance, six TtAP2/ERF genes from the ERF subfamily (TtAP2/ERF-090, TtAP2/ERF-107, TtAP2/ERF-051, TtAP2/ERF-068, TtAP2/ERF-201, and TtAP2/ERF-229) were highly upregulated under both drought and heat stress conditions. Several key cis-regulatory elements such as the dehydration-responsive element (DRE) with conserved sequence [AG]CCGAC, ABA-responsive element (ABRE B) with conserved sequence TCCACGTCTC, re2f-1 element with 
conserved sequence GCGGGAAA, and ACGT motif with conserved sequence GTACGTG were observed in the promoter site $(-1500 \mathrm{bp}$ from start codon) of upregulated genes under both drought and heat stresses (data not shown). The presence of these common regulatory elements in the promoter region of upregulated genes seems to affect the induction of these genes in both drought and heat stress conditions. In agreement with our findings, Cui et al. also suggested that, compared with those of $A P 2 s$, the expression levels of $E R F$ subfamily members from $B$. distachyon were more induced after heavy metal, cold, drought, and salt exposure [34]. These differences in expression may be due to the longer exons and/or lack of introns in ERF subfamily genes, which may lead to a faster response and greater expression of these genes during the stress response compared to that of the AP2 subfamily genes in durum wheat $[81,94]$. It has been widely suggested that AP2/ERF proteins can bind to GCC-box or DRE motifs through their MG metal ion in the AP2 domain, altering the target gene expression under stress conditions $[19,20,95]$. Previous studies have also illustrated that the genes encoding DREB proteins are significantly cold and drought responsive, so overexpression of these genes could improve drought, salt, and cold tolerance in plants $[19,81,95]$. Furthermore, DRE is a core sequence of genes involved in the response to drought and cold stresses $[3,18,96]$. A DREB2 homolog Wdreb2 gene, which was firstly isolated from bread wheat, is activated by abiotic stresses such as salt, drought, cold, and exogenous ABA application [97]. In the current study, we found two orthologues of Wdreb2, TtAP2/ERF-001, and TtAP2/ERF-017, from genome of durum wheat, which both orthologues genes showed an upregulation in response to heat stress.

$A P 2 / E R F$ s are considered dynamic genes involved in development and stress response processes. Fan et al. stated that most of the tested ERF genes in cassava were upregulated in response to osmotic and salt stresses [82]. The AtERF53 gene in Arabidopsis has been reported to be a drought- and heat-induced transcription factor modulating drought and heat-responsive genes through binding to cis-elements, dehydration-responsive elements (DREs), and GCC-boxes of target gene promoters [98-100]. In addition, silencing of ERF54L and ERF4L decreased the salt tolerance of cotton seedlings [101]. Overexpression of ERF1 from pitahaya (Hylocereus undatus) in Arabidopsis could increase the activity of antioxidant enzymes and enhance salt tolerance [102]. It was also reported that the insect herbivore-responsive AP2/EFR in Arabidopsis, ORA47, has an important function in the adjustment of a suite of genes involved in biosynthesis and phytohormone signal transduction during wounding, in response to MeJA and during drought stress [103,104]. Interestingly, TtAP2/ERF-227, TtAP2/ERF-185, and TtAP2/ERF-009 showed close phylogenetic relationships with several genes from Arabidopsis, especially genes in the ERF group. According to various studies, most of these homologous genes in Arabidopsis are involved in modulating freezing, dehydration, and salinity tolerance via activation of an ABA-responsive network and stress-related genes [105-107]. Evidence revealed that $T t A P 2 \mathrm{~s} / E R F \mathrm{~s}$ might be positively involved in the regulation of salt and drought tolerance in durum wheat. The variable gene transcription patterns obtained from the RT-qPCR-based experiment in the current study showed that most TtAP2s/ERFs, such as TtAP2/ERF-271, TtAP2/ERF-185, TtAP2/ERF-099, TtAP2/ERF-206, and TtAP2/ERF-070, may function in mediate as an intricate network for multiple stimulus responses and adaptations. This phenomenon may rely on the presence of a great number of experimentally accredited stress-related motifs and regulatory residues in the active region of these proteins [108,109]. Markedly high transcript levels in response to stresses were detected for members belonging to the ERF gene subfamily compared with the AP2 gene subfamily, and members of $D R E B$ illustrated high expression in response to heat and drought stresses. These differences in expression may be due to the longer exons and/or lack of introns in ERF subfamily genes, which can lead to an extreme reaction and excessive transcription of these genes during plant development and stress exposure, compared to AP2s [81,94]. Members of the AP2/ERF gene family have apposite functions, transcription repression, or activation of the downstream genes $[53,54]$. In the present study, the conserved sequences of three identified repression motifs ([R/K]LFGV, FDLNLPP, and EDLL) were detected into the protein sequence of $T t A P 2 \mathrm{~s} / E R F \mathrm{~s}$. The R/KLFGV motif as a repression sequence is distributed in the RAV subfamily [54], while FDLNLPP and EDLL were originally found in the ERF 
subfamily [53,97]. According to expression profile, most genes that contained a repression motif are not induced by heat and drought stresses in durum wheat, indicating that TtAP2/ERFs with activation functions are more involved in response to drought and heat stress. The downregulation of several TtAP2s/ERFs in this study may play a vital function in the transcriptional adjustment of stress-related genes. These findings indicated that decreased expression of $A P 2 / E R F$ s under stress conditions can help to retain the osmotic potential of plant cell membranes, which ultimately can lead to the accumulation of harmful substances in transport vesicles to inhibit phytotoxic effects [19,95], constituting an initial protection system in dealing with stresses. These results suggest that TtAP2/ERF genes may be vastly involved in various developmental systems and abiotic stress responses in durum wheat.

\section{Conclusions}

AP2/ERF TFs, which are important regulators of plant growth, development, and stress response, have been studied in depth in several crop species. The present study distinguished and identified 271 members of the AP2/ERF gene family in the durum wheat genome, which may facilitate the functional analysis of the other AP2/ERF genes in the future. Our bioinformatics analyses and expression profiling provide novel insights into the biological function of these TtAP2/ERF genes. Our findings can be effective for elucidating the highly unrecognized $A P 2 / E R F$-mediated signaling pathways that are critical for the survival of plants under abiotic stress conditions and may provide new opportunities to discover more stress adaptation mechanisms in durum wheat and other plant species.

Supplementary Materials: The following are available online at http://www.mdpi.com/2073-4425/11/12/1464/s1, Table S1: List of primers used for expression assay of the candidate AP2/ERF genes; Table S2: List of the identified $T t A P 2 / E R F$ genes and their characteristics in the durum wheat genome; Table S3: List of the conserved protein motifs predicted in TtAP2/ERF sequences from durum wheat; Table S4: Duplicated gene pairs and the Ka/Ks values predicted in TtAP2/ERF gene family in the durum wheat genome; Figure S1: Phylogenetic relationships of the 271 non-redundant putative TtAP2/ERF proteins predicted from the T. turgidum genome according to MEGA software (v. 6.0) based on the neighbor-joining (NJ) method. The 15 conserved motifs have been identified and listed in front of each protein.

Author Contributions: S.F. and S.K.K. designed the study. S.F., E.F., and P.H. conducted the experiments and analyzed the data. All authors contributed to writing the manuscript. A.V., F.P., and G.B. contributed to the interpretation, presentation and discussion of the data. All authors contributed to writing and editing the manuscript. All authors have read and agreed to the published version of the manuscript.

Funding: This research received no external funding.

Acknowledgments: The authors warmly appreciate the Pasteur Biotechnology Institute of Tehran and Mohammadreza Fazeli for their support and cooperation.

Conflicts of Interest: The authors declare no conflict of interest.

\section{References}

1. Yamaguchi-Shinozaki, K.; Shinozaki, K. Transcriptional regulatory networks in cellular responses and tolerance to dehydration and cold stresses. Annu. Rev. Plant Biol. 2006, 57, 781-803. [CrossRef] [PubMed]

2. Heidari, P.; Mazloomi, F.; Nussbaumer, T.; Barcaccia, G. Insights into the SAM Synthetase Gene Family and Its Roles in Tomato Seedlings under Abiotic Stresses and Hormone Treatments. Plants 2020, 9, 586. [CrossRef] [PubMed]

3. Lata, C.; Prasad, M. Role of DREBs in regulation of abiotic stress responses in plants. J. Exp. Bot. 2011, 62, 4731-4748. [CrossRef]

4. Ahmadizadeh, M.; Heidari, P. Bioinformatics study of transcription factors involved in cold stress. Biharean Biol. 2014, 8, 83-86.

5. Chen, L.; Han, J.; Deng, X.; Tan, S.; Li, L.; Li, L.; Zhou, J.; Peng, H.; Yang, G.; He, G. Expansion and stress responses of AP2/EREBP superfamily in Brachypodium distachyon. Sci. Rep. 2016, 6, 1-14. [CrossRef] [PubMed]

6. Rezaee, S.; Ahmadizadeh, M.; Heidari, P. Genome-wide characterization, expression profiling, and posttranscriptional study of GASA gene family. Gene Rep. 2020, 20, 100795. [CrossRef] 
7. Feng, K.; Hou, X.-L.; Xing, G.-M.; Liu, J.-X.; Duan, A.-Q.; Xu, Z.-S.; Li, M.-Y.; Zhuang, J.; Xiong, A.-S. Advances in AP2/ERF super-family transcription factors in plant. Crit. Rev. Biotechnol. 2020, 40, 750-776. [CrossRef]

8. Ito, Y.; Katsura, K.; Maruyama, K.; Taji, T.; Kobayashi, M.; Seki, M.; Shinozaki, K.; Yamaguchi-Shinozaki, K. Functional analysis of rice DREB1/CBF-type transcription factors involved in cold-responsive gene expression in transgenic rice. Plant Cell Physiol. 2006, 47, 141-153. [CrossRef]

9. Sharoni, A.M.; Nuruzzaman, M.; Satoh, K.; Shimizu, T.; Kondoh, H.; Sasaya, T.; Choi, I.-R.; Omura, T.; Kikuchi, S. Gene structures, classification and expression models of the AP2/EREBP transcription factor family in rice. Plant Cell Physiol. 2011, 52, 344-360. [CrossRef]

10. Karanja, B.K.; Xu, L.; Wang, Y.; Tang, M.; Muleke, E.M.; Dong, J.; Liu, L. Genome-wide characterization of the AP2/ERF gene family in radish (Raphanus sativus L.): Unveiling evolution and patterns in response to abiotic stresses. Gene 2019, 718, 144048. [CrossRef]

11. Feng, J.-X.; Liu, D.; Pan, Y.; Gong, W.; Ma, L.-G.; Luo, J.-C.; Deng, X.W.; Zhu, Y.-X. An annotation update via cDNA sequence analysis and comprehensive profiling of developmental, hormonal or environmental responsiveness of the Arabidopsis AP2/EREBP transcription factor gene family. Plant Mol. Biol. 2005, 59, 853-868. [CrossRef] [PubMed]

12. Zhuang, J.; Chen, J.-M.; Yao, Q.-H.; Xiong, F.; Sun, C.-C.; Zhou, X.-R.; Zhang, J.; Xiong, A.-S. Discovery and expression profile analysis of AP2/ERF family genes from Triticum aestivum. Mol. Biol. Rep. 2011, 38, 745-753. [CrossRef] [PubMed]

13. Zhang, G.; Chen, M.; Chen, X.; Xu, Z.; Guan, S.; Li, L.-C.; Li, A.; Guo, J.; Mao, L.; Ma, Y. Phylogeny, gene structures, and expression patterns of the ERF gene family in soybean (Glycine max L.). J. Exp. Bot. 2008, 59, 4095-4107. [CrossRef] [PubMed]

14. Owji, H.; Hajiebrahimi, A.; Seradj, H.; Hemmati, S. Identification and functional prediction of stress responsive AP2/ERF transcription factors in Brassica napus by genome-wide analysis. Comput. Biol. Chem. 2017, 71, 32-56. [CrossRef]

15. Jin, X.; Yin, X.; Ndayambaza, B.; Zhang, Z.; Min, X.; Lin, X.; Wang, Y.; Liu, W. Genome-wide identification and expression profiling of the ERF gene family in Medicago sativa L. under various abiotic stresses. DNA Cell Biol. 2019, 38, 1056-1068. [CrossRef]

16. Huang, Y.; Liu, Y.; Zhang, M.; Chai, M.; He, Q.; Jakada, B.H.; Chen, F.; Chen, H.; Jin, X.; Cai, H. Genome-wide identification and expression analysis of the ERF transcription factor family in pineapple (Ananas comosus (L.) Merr.). PeerJ 2020, 8, e10014. [CrossRef]

17. Ya-Ting, H.U.; Zhi-Chao, X.U.; Ya, T.; Ran-Ran, G.A.O.; Ai-Jia, J.I.; Xiang-Dong, P.U.; Yu, W.; Xia, L.I.U.; Jing-Yuan, S. Genome-wide identification and analysis of AP2/ERF transcription factors related to camptothecin biosynthesis in Camptotheca acuminata. Chin. J. Nat. Med. 2020, 18, 582-593.

18. Xu, L.; Feng, G.; Yang, Z.; Xu, X.; Huang, L.; Yang, Q.; Zhang, X. Genome-wide AP2/ERF gene family analysis reveals the classification, structure, expression profiles and potential function in orchardgrass (Dactylis glomerata). Mol. Biol. Rep. 2020, 47, 5225-5241. [CrossRef]

19. Lata, C.; Mishra, A.K.; Muthamilarasan, M.; Bonthala, V.S.; Khan, Y.; Prasad, M. Genome-wide investigation and expression profiling of AP2/ERF transcription factor superfamily in foxtail millet (Setaria italica L.). PLoS ONE 2014, 9, e113092. [CrossRef]

20. Mathur, S.; Priyadarshini, S.S.; Singh, V.; Vashisht, I.; Jung, K.-H.; Sharma, R.; Sharma, M.K. Comprehensive phylogenomic analysis of ERF genes in sorghum provides clues to the evolution of gene functions and redundancy among gene family members. 3 Biotech 2020, 10, 1-16. [CrossRef]

21. Chen, J.; Zhou, Y.; Zhang, Q.; Liu, Q.; Li, L.; Sun, C.; Wang, K.; Wang, Y.; Zhao, M.; Li, H. Structural variation, functional differentiation and expression characteristics of the AP2/ERF gene family and its response to cold stress and methyl jasmonate in Panax ginseng CA Meyer. PLoS ONE 2020, 15, e0226055. [CrossRef] [PubMed]

22. Xu, S.; Yao, S.; Huang, R.; Tan, Y.; Huang, D. Transcriptome-wide analysis of the AP2/ERF transcription factor gene family involved in the regulation of gypenoside biosynthesis in Gynostemma pentaphyllum. Plant Physiol. Biochem. 2020. [CrossRef] [PubMed]

23. Aukerman, M.J.; Sakai, H. Regulation of flowering time and floral organ identity by a microRNA and its APETALA2-like target genes. Plant Cell 2003, 15, 2730-2741. [CrossRef] [PubMed]

24. Jofuku, K.D.; Omidyar, P.K.; Gee, Z.; Okamuro, J.K. Control of seed mass and seed yield by the floral homeotic gene APETALA2. Proc. Natl. Acad. Sci. USA 2005, 102, 3117-3122. [CrossRef] [PubMed] 
25. Taketa, S.; Amano, S.; Tsujino, Y.; Sato, T.; Saisho, D.; Kakeda, K.; Nomura, M.; Suzuki, T.; Matsumoto, T.; Sato, K. Barley grain with adhering hulls is controlled by an ERF family transcription factor gene regulating a lipid biosynthesis pathway. Proc. Natl. Acad. Sci. USA 2008, 105, 4062-4067. [CrossRef] [PubMed]

26. Hu, Y.X.; Wang, Y.H.; Liu, X.F.; Li, J.Y. Arabidopsis RAV1 is down-regulated by brassinosteroid and may act as a negative regulator during plant development. Cell Res. 2004, 14, 8-15. [CrossRef]

27. Sohn, K.H.; Lee, S.C.; Jung, H.W.; Hong, J.K.; Hwang, B.K. Expression and functional roles of the pepper pathogen-induced transcription factor RAV1 in bacterial disease resistance, and drought and salt stress tolerance. Plant Mol. Biol. 2006, 61, 897-915. [CrossRef]

28. Huang, X.; Song, X.; Chen, R.; Zhang, B.; Li, C.; Liang, Y.; Qiu, L.; Fan, Y.; Zhou, Z.; Zhou, H. Genome-Wide Analysis of the DREB Subfamily in Saccharum spontaneum Reveals Their Functional Divergence During Cold and Drought Stresses. Front. Genet. 2020, 10, 1326. [CrossRef]

29. Latini, A.; Sperandei, M.; Cantale, C.; Arcangeli, C.; Ammar, K.; Galeffi, P. Variability and expression profile of the DRF1 gene in four cultivars of durum wheat and one triticale under moderate water stress conditions. Planta 2013, 237, 967-978. [CrossRef]

30. Latini, A.; Rasi, C.; Sperandei, M.; Cantale, C.; Iannetta, M.; Dettori, M.; Ammar, K.; Galeffi, P. Identification of a DREB-related gene in Triticum durum and its expression under water stress conditions. Ann. Appl. Biol. 2007, 150, 187-195. [CrossRef]

31. Cao, S.; Wang, Y.; Li, X.; Gao, F.; Feng, J.; Zhou, Y. Characterization of the AP2/ERF Transcription Factor Family and Expression Profiling of DREB Subfamily under Cold and Osmotic Stresses in Ammopiptanthus nanus. Plants 2020, 9, 455. [CrossRef] [PubMed]

32. Makhloufi, E.; Yousfi, F.-E.; Marande, W.; Mila, I.; Hanana, M.; Bergès, H.; Mzid, R.; Bouzayen, M. Isolation and molecular characterization of ERF1, an ethylene response factor gene from durum wheat (Triticum turgidum L. subsp. durum), potentially involved in salt-stress responses. J. Exp. Bot. 2014, 65, 6359-6371. [CrossRef] [PubMed]

33. Sun, Z.-M.; Zhou, M.-L.; Xiao, X.-G.; Tang, Y.-X.; Wu, Y.-M. Genome-wide analysis of AP2/ERF family genes from Lotus corniculatus shows LcERF054 enhances salt tolerance. Funct. Integr. Genom. 2014, 14, 453-466. [CrossRef] [PubMed]

34. Cui, L.; Feng, K.; Wang, M.; Wang, M.; Deng, P.; Song, W.; Nie, X. Genome-wide identification, phylogeny and expression analysis of AP2/ERF transcription factors family in Brachypodium distachyon. BMC Genomics 2016, 17, 636. [CrossRef]

35. Kavas, M.; Kizildogan, A.; Gökdemir, G.; Baloglu, M.C. Genome-wide investigation and expression analysis of AP2-ERF gene family in salt tolerant common bean. EXCLI J. 2015, 14, 1187-1206.

36. Ma, Z.; Wu, T.; Huang, K.; Jin, Y.-M.; Li, Z.; Chen, M.; Yun, S.; Zhang, H.; Yang, X.; Chen, H. A Novel AP2/ERF Transcription Factor, OsRPH1, Negatively Regulates Plant Height in Rice. Front. Plant Sci. 2020, 11, 11. [CrossRef]

37. Zang, Z.; Lv, Y.; Liu, S.; Yang, W.; Ci, J.; Ren, X.; Wang, Z.; Wu, H.; Ma, W.; Jiang, L. A Novel ERF Transcription Factor, ZmERF105, Positively Regulates Maize Resistance to Exserohilum turcicum. Front. Plant Sci. 2020, 11, 850. [CrossRef]

38. Paul, P.; Singh, S.K.; Patra, B.; Liu, X.; Pattanaik, S.; Yuan, L. Mutually regulated AP2/ERF gene clusters modulate biosynthesis of specialized metabolites in plants. Plant Physiol. 2020, 182, 840-856. [CrossRef]

39. Huang, Q.; Sun, M.; Yuan, T.; Wang, Y.; Shi, M.; Lu, S.; Tang, B.; Pan, J.; Wang, Y.; Kai, G. The AP2/ERF transcription factor SmERF1L1 regulates the biosynthesis of tanshinones and phenolic acids in Salvia miltiorrhiza. Food Chem. 2019, 274, 368-375. [CrossRef]

40. Morran, S.; Eini, O.; Pyvovarenko, T.; Parent, B.; Singh, R.; Ismagul, A.; Eliby, S.; Shirley, N.; Langridge, P.; Lopato, S. Improvement of stress tolerance of wheat and barley by modulation of expression of DREB/CBF factors. Plant Biotechnol. J. 2011, 9, 230-249. [CrossRef]

41. Bolser, D.M.; Staines, D.M.; Perry, E.; Kersey, P.J. Ensembl plants: Integrating tools for visualizing, mining, and analyzing plant genomic data. In Plant Genomics Databases; Springer: Berlin, Germany, 2017; pp. 1-31.

42. Finn, R.D.; Mistry, J.; Tate, J.; Coggill, P.; Heger, A.; Pollington, J.E.; Gavin, O.L.; Gunasekaran, P.; Ceric, G.; Forslund, K. The Pfam protein families database. Nucleic Acids Res. 2010, 38, D211-D222. [CrossRef] [PubMed]

43. Schultz, J.; Copley, R.R.; Doerks, T.; Ponting, C.P.; Bork, P. SMART: A web-based tool for the study of genetically mobile domains. Nucleic Acids Res. 2000, 28, 231-234. [CrossRef] [PubMed] 
44. Gasteiger, E.; Gattiker, A.; Hoogland, C.; Ivanyi, I.; Appel, R.D.; Bairoch, A. ExPASy: The proteomics server for in-depth protein knowledge and analysis. Nucleic Acids Res. 2003, 31, 3784-3788. [CrossRef] [PubMed]

45. Yu, C.; Chen, Y.; Lu, C.; Hwang, J. Prediction of protein subcellular localization. Proteins Struct. Funct. Bioinf. 2006, 64, 643-651. [CrossRef]

46. Voorrips, R.E. MapChart: Software for the graphical presentation of linkage maps and QTLs. J. Hered. 2002, 93, 77-78. [CrossRef]

47. Larkin, M.A.; Blackshields, G.; Brown, N.P.; Chenna, R.; McGettigan, P.A.; McWilliam, H.; Valentin, F.; Wallace, I.M.; Wilm, A.; Lopez, R. Clustal W and Clustal X version 2.0. Bioinformatics 2007, 23, 2947-2948. [CrossRef]

48. Hall, T.A. BioEdit: A user-friendly biological sequence alignment editor and analysis program for Windows 95/98/NT. In Nucleic Acids Symposium Series; Oxford University Press: London, UK, 1999; Volume 41, pp. $95-98$.

49. Rozas, J.; Ferrer-Mata, A.; Sánchez-DelBarrio, J.C.; Guirao-Rico, S.; Librado, P.; Ramos-Onsins, S.E.; Sánchez-Gracia, A. DnaSP 6: DNA sequence polymorphism analysis of large data sets. Mol. Biol. Evol. 2017, 34, 3299-3302. [CrossRef]

50. Jin, J.; Tian, F.; Yang, D.-C.; Meng, Y.-Q.; Kong, L.; Luo, J.; Gao, G. PlantTFDB 4.0: Toward a central hub for transcription factors and regulatory interactions in plants. Nucleic Acids Res. 2016, 45, D1040-D1045. [CrossRef]

51. Tamura, K.; Stecher, G.; Peterson, D.; Filipski, A.; Kumar, S. MEGA6: Molecular evolutionary genetics analysis version 6.0. Mol. Biol. Evol. 2013, 30, 2725-2729. [CrossRef]

52. Bailey, T.L.; Boden, M.; Buske, F.A.; Frith, M.; Grant, C.E.; Clementi, L.; Ren, J.; Li, W.W.; Noble, W.S. MEME SUITE: Tools for motif discovery and searching. Nucleic Acids Res. 2009, 37, W202-W208. [CrossRef]

53. Ohta, M.; Matsui, K.; Hiratsu, K.; Shinshi, H.; Ohme-Takagi, M. Repression domains of class II ERF transcriptional repressors share an essential motif for active repression. Plant Cell 2001, 13, 1959-1968. [CrossRef] [PubMed]

54. Ikeda, M.; Ohme-Takagi, M. A novel group of transcriptional repressors in Arabidopsis. Plant Cell Physiol. 2009, 50, 970-975. [CrossRef] [PubMed]

55. Tiwari, S.B.; Belachew, A.; Ma, S.F.; Young, M.; Ade, J.; Shen, Y.; Marion, C.M.; Holtan, H.E.; Bailey, A.; Stone, J.K. The EDLL motif: A potent plant transcriptional activation domain from AP2/ERF transcription factors. Plant J. 2012, 70, 855-865. [CrossRef] [PubMed]

56. Madeira, F.; Park, Y.M.; Lee, J.; Buso, N.; Gur, T.; Madhusoodanan, N.; Basutkar, P.; Tivey, A.R.N.; Potter, S.C.; Finn, R.D. The EMBL-EBI search and sequence analysis tools APIs in 2019. Nucleic Acids Res. 2019, 47, W636-W641. [CrossRef]

57. Yang, J.; Yan, R.; Roy, A.; Xu, D.; Poisson, J.; Zhang, Y. The I-TASSER Suite: Protein structure and function prediction. Nat. Methods 2015, 12,7-8. [CrossRef]

58. Bhattacharya, D.; Nowotny, J.; Cao, R.; Cheng, J. 3Drefine: An interactive web server for efficient protein structure refinement. Nucleic Acids Res. 2016, 44, W406-W409. [CrossRef]

59. Lovell, S.C.; Davis, I.W.; Arendall, W.B., III; De Bakker, P.I.W.; Word, J.M.; Prisant, M.G.; Richardson, J.S.; Richardson, D.C. Structure validation by $\mathrm{C} \alpha$ geometry: $\phi, \psi$ and $C \beta$ deviation. Proteins Struct. Funct. Bioinf. 2003, 50, 437-450. [CrossRef]

60. Jendele, L.; Krivak, R.; Skoda, P.; Novotny, M.; Hoksza, D. PrankWeb: A web server for ligand binding site prediction and visualization. Nucleic Acids Res. 2019, 47, W345-W349. [CrossRef]

61. Xu, Y.; Wang, S.; Hu, Q.; Gao, S.; Ma, X.; Zhang, W.; Shen, Y.; Chen, F.; Lai, L.; Pei, J. CavityPlus: A web server for protein cavity detection with pharmacophore modelling, allosteric site identification and covalent ligand binding ability prediction. Nucleic Acids Res. 2018, 46, W374-W379. [CrossRef]

62. DeLano, W.L. Pymol: An open-source molecular graphics tool. CCP4 Newsl. Protein Crystallogr. 2002, 40, 82-92.

63. Chen, C.; Chen, H.; Zhang, Y.; Thomas, H.R.; Frank, M.H.; He, Y.; Xia, R. TBtools-an integrative toolkit developed for interactive analyses of big biological data. bioRxiv 2020, 289660. [CrossRef] [PubMed]

64. Untergasser, A.; Cutcutache, I.; Koressaar, T.; Ye, J.; Faircloth, B.C.; Remm, M.; Rozen, S.G. Primer3-New capabilities and interfaces. Nucleic Acids Res. 2012, 40, e115. [CrossRef] [PubMed]

65. Livak, K.J.; Schmittgen, T.D. Analysis of Relative Gene Expression Data Using Real-Time Quantitative PCR and the 2- $\Delta \Delta \mathrm{CT}$ Method. Methods 2001, 25, 402-408. [CrossRef] [PubMed] 
66. Liu, Y.; Zhao, T.-J.; Liu, J.-M.; Liu, W.-Q.; Liu, Q.; Yan, Y.-B.; Zhou, H.-M. The conserved Ala37 in the ERF/AP2 domain is essential for binding with the DRE element and the GCC box. FEBS Lett. 2006, 580, 1303-1308. [CrossRef]

67. Nakano, T.; Suzuki, K.; Fujimura, T.; Shinshi, H. Genome-wide analysis of the ERF gene family in Arabidopsis and rice. Plant Physiol. 2006, 140, 411-432. [CrossRef]

68. Kiełbowicz-Matuk, A. Involvement of plant $\mathrm{C} 2 \mathrm{H} 2$-type zinc finger transcription factors in stress responses. Plant Sci. 2012, 185, 78-85. [CrossRef]

69. Razin, S.V.; Borunova, V.V.; Maksimenko, O.G.; Kantidze, O.L. Cys2His2 zinc finger protein family: Classification, functions, and major members. Biochemisty 2012, 77, 217-226. [CrossRef]

70. Mandal, P.K.; Rai, S.; Kaushik, M.; Sinha, S.K.; Gupta, R.K.; Mahendru, A. Transcriptome data of cultivated tetraploid and hexaploid wheat variety during grain development. Data Br. 2019, 22, 551-556. [CrossRef]

71. Sauer, M.; Paciorek, T.; Benková, E.; Friml, J. Immunocytochemical techniques for whole-mount in situ protein localization in plants. Nat. Protoc. 2006, 1, 98-103. [CrossRef]

72. Dietz, K.-J.; Vogel, M.O.; Viehhauser, A. AP2/EREBP transcription factors are part of gene regulatory networks and integrate metabolic, hormonal and environmental signals in stress acclimation and retrograde signalling. Protoplasma 2010, 245, 3-14. [CrossRef]

73. Herath, V. Small family, big impact: In silico analysis of DREB2 transcription factor family in rice. Comput. Biol. Chem. 2016, 65, 128-139. [CrossRef] [PubMed]

74. Sakuma, Y.; Maruyama, K.; Qin, F.; Osakabe, Y.; Shinozaki, K.; Yamaguchi-Shinozaki, K. Dual function of an Arabidopsis transcription factor DREB2A in water-stress-responsive and heat-stress-responsive gene expression. Proc. Natl. Acad. Sci. USA 2006, 103, 18822-18827. [CrossRef] [PubMed]

75. Yang, Z. Cell polarity signaling in Arabidopsis. Annu. Rev. Cell Dev. Biol. 2008, 24, 551-575. [CrossRef] [PubMed]

76. Heidari, P.; Ahmadizadeh, M.; Izanlo, F.; Nussbaumer, T. In silico study of the CESA and CSL gene family in Arabidopsis thaliana and Oryza sativa: Focus on post-translation modifications. Plant Gene 2019, 19, 100189. [CrossRef]

77. Juretic, N.; Hoen, D.R.; Huynh, M.L.; Harrison, P.M.; Bureau, T.E. The evolutionary fate of MULE-mediated duplications of host gene fragments in rice. Genome Res. 2005, 15, 1292-1297. [CrossRef]

78. Wang, P.; Su, L.; Gao, H.; Jiang, X.; Wu, X.; Li, Y.; Zhang, Q.; Wang, Y.; Ren, F. Genome-wide characterization of bHLH genes in grape and analysis of their potential relevance to abiotic stress tolerance and secondary metabolite biosynthesis. Front. Plant Sci. 2018, 9, 64. [CrossRef]

79. Singh, A.; Kanwar, P.; Pandey, A.; Tyagi, A.K.; Sopory, S.K.; Kapoor, S.; Pandey, G.K. Comprehensive genomic analysis and expression profiling of phospholipase $C$ gene family during abiotic stresses and development in rice. PLOS ONE 2013, 8, e62494. [CrossRef]

80. Wang, Y.; Tang, H.; DeBarry, J.D.; Tan, X.; Li, J.; Wang, X.; Lee, T.; Jin, H.; Marler, B.; Guo, H. MCScanX: A toolkit for detection and evolutionary analysis of gene synteny and collinearity. Nucleic Acids Res. 2012, 40, e49. [CrossRef]

81. Shu, Y.; Liu, Y.; Zhang, J.; Song, L.; Guo, C. Genome-wide analysis of the AP2/ERF superfamily genes and their responses to abiotic stress in Medicago truncatula. Front. Plant Sci. 2016, 6, 1247. [CrossRef]

82. Fan, W.; Hai, M.; Guo, Y.; Ding, Z.; Tie, W.; Ding, X.; Yan, Y.; Wei, Y.; Liu, Y.; Wu, C. The ERF transcription factor family in cassava: Genome-wide characterization and expression analyses against drought stress. Sci. Rep. 2016, 6, 37379. [CrossRef]

83. Okamuro, J.K.; Caster, B.; Villarroel, R.; Van Montagu, M.; Jofuku, K.D. The AP2 domain of APETALA2 defines a large new family of DNA binding proteins in Arabidopsis. Proc. Natl. Acad. Sci. USA 1997, 94, 7076-7081. [CrossRef] [PubMed]

84. Stank, A.; Kokh, D.B.; Fuller, J.C.; Wade, R.C. Protein binding pocket dynamics. Acc. Chem. Res. 2016, 49, 809-815. [CrossRef] [PubMed]

85. Wang, L.; Berne, B.J.; Friesner, R.A. Ligand binding to protein-binding pockets with wet and dry regions. Proc. Natl. Acad. Sci. USA 2011, 108, 1326-1330. [CrossRef] [PubMed]

86. Hormoz, S. Amino acid composition of proteins reduces deleterious impact of mutations. Sci. Rep. 2013, 3, 2919. [CrossRef] 
87. Mousavi, A.; Hotta, Y. Glycine-rich proteins. Appl. Biochem. Biotechnol. 2005, 120, 169-174. [CrossRef]

88. Beauregard, M.; Hefford, M.A. Enhancement of essential amino acid contents in crops by genetic engineering and protein design. Plant Biotechnol. J. 2006, 4, 561-574. [CrossRef]

89. Galili, G.; Höfgen, R. Metabolic engineering of amino acids and storage proteins in plants. Metab. Eng. 2002, 4, 3-11. [CrossRef]

90. Yang, Q.; Zhao, D.; Liu, Q. Connections Between Amino Acid Metabolisms in Plants: Lysine as an Example. Front. Plant Sci. 2020, 11, 928. [CrossRef]

91. Grunwell, J.R.; Rath, V.L.; Rasmussen, J.; Cabrilo, Z.; Bertozzi, C.R. Characterization and mutagenesis of Gal/GlcNAc-6-O-sulfotransferases. Biochemistry 2002, 41, 15590-15600. [CrossRef]

92. Hiruma, K.; Fukunaga, S.; Bednarek, P.; Piślewska-Bednarek, M.; Watanabe, S.; Narusaka, Y.; Shirasu, K.; Takano, Y. Glutathione and tryptophan metabolism are required for Arabidopsis immunity during the hypersensitive response to hemibiotrophs. Proc. Natl. Acad. Sci. USA 2013, 110, 9589-9594. [CrossRef]

93. Muthamilarasan, M.; Bonthala, V.S.; Mishra, A.K.; Khandelwal, R.; Khan, Y.; Roy, R.; Prasad, M. $\mathrm{C}_{2} \mathrm{H}_{2}$ type of zinc finger transcription factors in foxtail millet define response to abiotic stresses. Funct. Integr. Genomics 2014, 14, 531-543. [CrossRef] [PubMed]

94. Mizoi, J.; Shinozaki, K.; Yamaguchi-Shinozaki, K. AP2/ERF family transcription factors in plant abiotic stress responses. Biochim. Biophys. Acta (BBA)-Gene Regul. Mech. 2012, 1819, 86-96. [CrossRef] [PubMed]

95. Shigyo, M.; Hasebe, M.; Ito, M. Molecular evolution of the AP2 subfamily. Gene 2006, 366, $256-265$. [CrossRef] [PubMed]

96. Heidari, P. Comparative Analysis of C-repeat Binding Factors (CBFs) in Tomato and Arabidopsis. Brazilian Arch. Biol. Technol. 2019, 62, e19180715. [CrossRef]

97. Egawa, C.; Kobayashi, F.; Ishibashi, M.; Nakamura, T.; Nakamura, C.; Takumi, S. Differential regulation of transcript accumulation and alternative splicing of a DREB2 homolog under abiotic stress conditions in common wheat. Genes Genet. Syst. 2006, 81, 77-91. [CrossRef]

98. Cheng, M.-C.; Hsieh, E.-J.; Chen, J.-H.; Chen, H.-Y.; Lin, T.-P. Arabidopsis RGLG2, functioning as a RING E3 ligase, interacts with AtERF53 and negatively regulates the plant drought stress response. Plant Physiol. 2012, 158, 363-375. [CrossRef]

99. Sakuma, Y.; Liu, Q.; Dubouzet, J.G.; Abe, H.; Shinozaki, K.; Yamaguchi-Shinozaki, K. DNA-binding specificity of the ERF/AP2 domain of Arabidopsis DREBs, transcription factors involved in dehydration-and cold-inducible gene expression. Biochem. Biophys. Res. Commun. 2002, 290, 998-1009. [CrossRef]

100. Shen, Y.-G.; Zhang, W.-K.; He, S.-J.; Zhang, J.-S.; Liu, Q.; Chen, S.-Y. An EREBP/AP2-type protein in Triticum aestivum was a DRE-binding transcription factor induced by cold, dehydration and ABA stress. Theor. Appl. Genet. 2003, 106, 923-930. [CrossRef]

101. Long, L.; Yang, W.-W.; Liao, P.; Guo, Y.-W.; Kumar, A.; Gao, W. Transcriptome analysis reveals differentially expressed ERF transcription factors associated with salt response in cotton. Plant Sci. 2019, 281, 72-81. [CrossRef]

102. Qu, Y.; Nong, Q.; Jian, S.; Lu, H.; Zhang, M.; Xia, K. An AP2/ERF Gene, HuERF1, from Pitaya (Hylocereus undatus) Positively Regulates Salt Tolerance. Int. J. Mol. Sci. 2020, 21, 4586. [CrossRef]

103. Chen, H.; Hsieh, E.; Cheng, M.; Chen, C.; Hwang, S.; Lin, T. ORA47 (octadecanoid-responsive AP2/ERF-domain transcription factor 47) regulates jasmonic acid and abscisic acid biosynthesis and signaling through binding to a novel cis-element. New Phytol. 2016, 211, 599-613. [CrossRef] [PubMed]

104. Rehrig, E.M.; Appel, H.M.; Jones, A.D.; Schultz, J.C. Roles for jasmonate-and ethylene-induced transcription factors in the ability of Arabidopsis to respond differentially to damage caused by two insect herbivores. Front. Plant Sci. 2014, 5, 407. [CrossRef] [PubMed]

105. Hu, Y.; Jiang, L.; Wang, F.; Yu, D. Jasmonate regulates the inducer of CBF expression-c-repeat binding factor/DRE binding factor1 cascade and freezing tolerance in Arabidopsis. Plant Cell 2013, 25, 2907-2924. [CrossRef] [PubMed]

106. Lee, S.Y.; Boon, N.J.; Webb, A.A.R.; Tanaka, R.J. Synergistic activation of RD29A via integration of salinity stress and abscisic acid in Arabidopsis thaliana. Plant Cell Physiol. 2016, 57, 2147-2160. [CrossRef] [PubMed]

107. Reis, R.R.; da Cunha, B.A.D.B.; Martins, P.K.; Martins, M.T.B.; Alekcevetch, J.C.; Chalfun-Júnior, A.; Andrade, A.C.; Ribeiro, A.P.; Qin, F.; Mizoi, J. Induced over-expression of AtDREB2A CA improves drought tolerance in sugarcane. Plant Sci. 2014, 221, 59-68. [CrossRef] 
108. Latini, A.; Sperandei, M.; Sharma, S.; Cantale, C.; Iannetta, M.; Dettori, M.; Ammar, K.; Galeffi, P. Molecular analyses of a dehydration-related gene from the DREB family in durum, wheat and triticale. In Biosaline Agriculture and High Salinity Tolerance; Springer: Berlin, Germany, 2008; pp. 287-295.

109. Rashotte, A.M.; Goertzen, L.R. The CRF domain defines cytokinin response factor proteins in plants. BMC Plant Biol. 2010, 10, 1-10. [CrossRef]

Publisher's Note: MDPI stays neutral with regard to jurisdictional claims in published maps and institutional affiliations.

(C) 2020 by the authors. Licensee MDPI, Basel, Switzerland. This article is an open access article distributed under the terms and conditions of the Creative Commons Attribution (CC BY) license (http://creativecommons.org/licenses/by/4.0/). 